\title{
RELAP5/MOD3.2 Assessment Using CHF Data from the KS-1 and V-200 Experiment Facilities
}

P. D. Bayless

July 2001 


\title{
RELAP5/MOD3.2 Assessment Using CHF Data from the KS-1 and V-200 Experiment Facilities
}

\author{
Paul D. Bayless
}

Published July 2001

Idaho National Engineering and Environmental Laboratory Idaho Falls, Idaho 83415

Prepared for the

U.S. Department of Energy

Assistant Secretary for Nonproliferation and National Security

Under DOE Idaho Operations Office

Contract DE-AC07-99ID13727 


\section{ABSTRACT}

The RELAP/MOD3.2 computer code has been assessed using rod bundle critical heat flux data from the KS-1 and V-200 facilities. This work was performed as part of the U.S. Department of Energy's International Nuclear Safety Program, and is part of the effort addressing the capability of the RELAP5/MOD3.2 code to model transients in Soviet-designed reactors.

Designated VVER Standard Problem 7, these tests addressed one of the important phenomena related to VVER behavior that the code needs to simulate well, core heat transfer. The code was judged to be in minimal agreement with the experiment data, consistently overpredicting the measured critical heat flux. It is recommended that a model development effort be undertaken to develop a critical heat flux model for RELAP5 that better represents the behavior in VVER rod bundles. 


\section{CONTENTS}

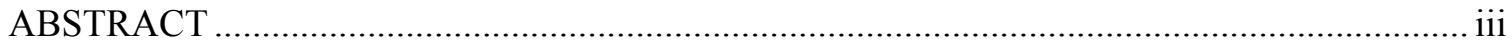

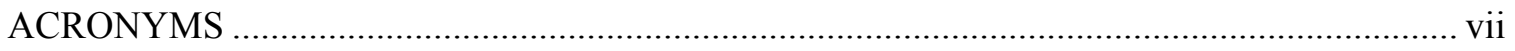

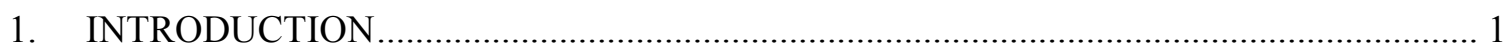

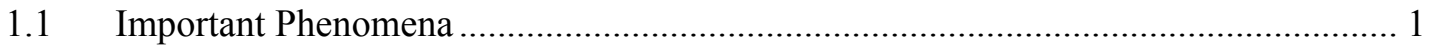

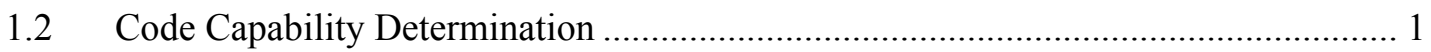

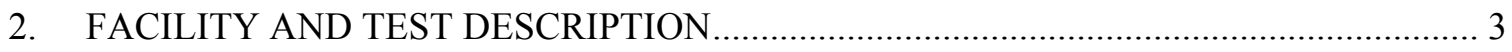

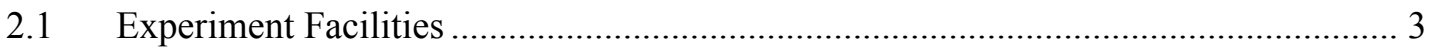

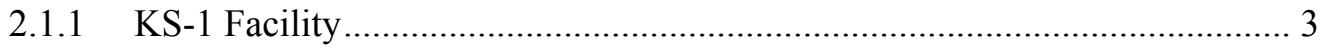

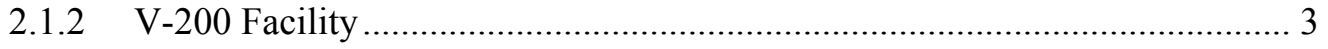

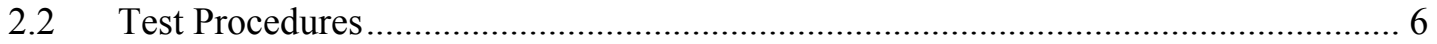

3. CODE AND INPUT MODEL DESCRIPTION ........................................................... 7

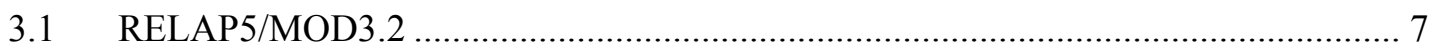

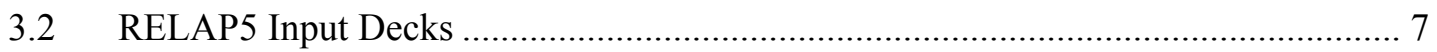

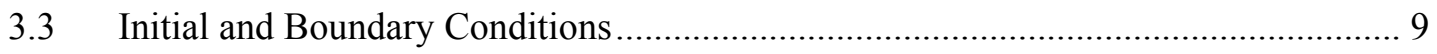

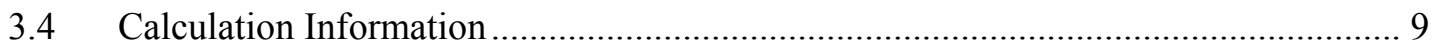

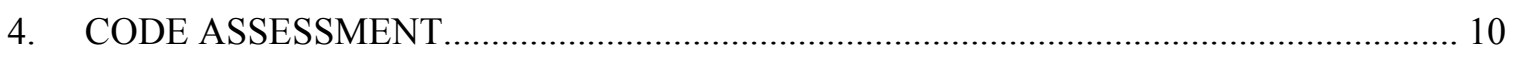

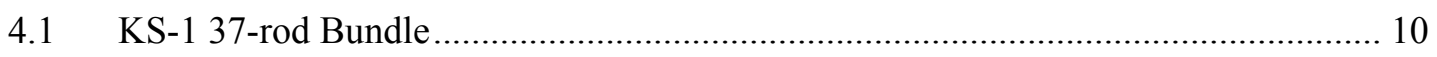

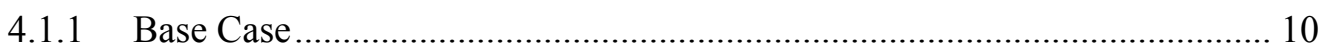

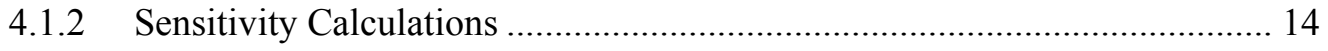

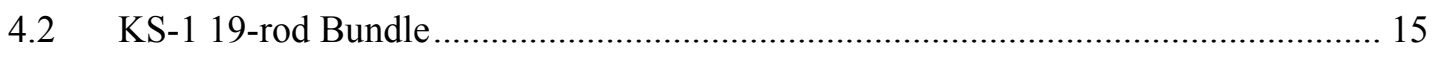

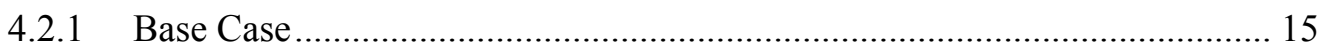

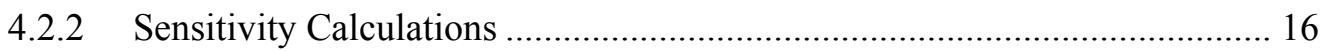

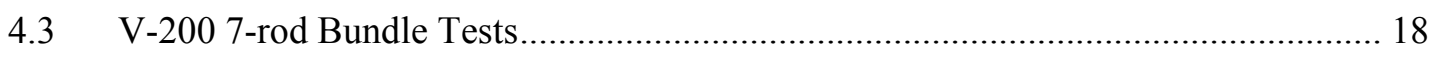

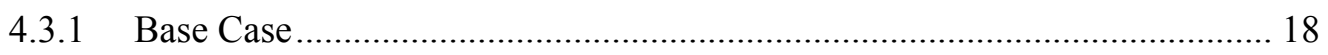

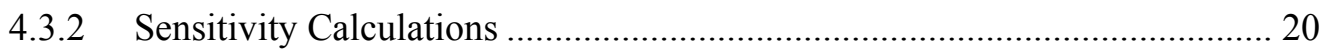

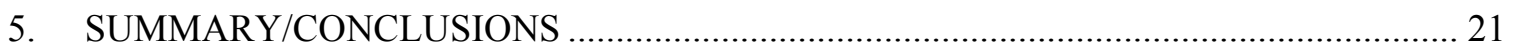

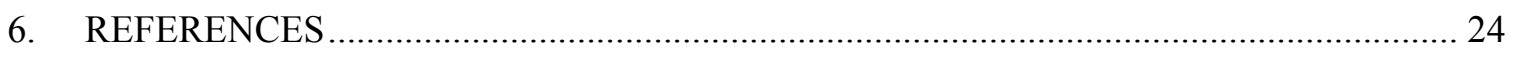

Appendix A - Input Listing for KS-1 37-rod Bundle RELAP5 Model ....................................... 25 


\section{FIGURES}

1. Geometric parameters of the KS-1 37-rod bundle. ….................................................... 4

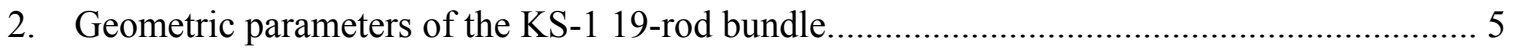

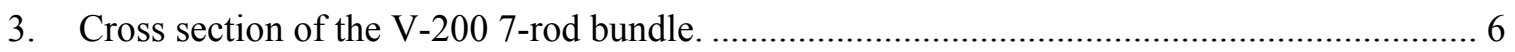

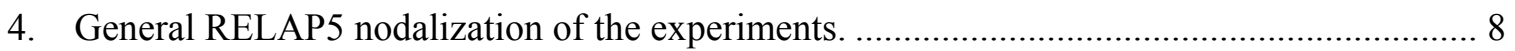

5. Calculated deviation from the measured CHF versus pressure for the KS-1 37-rod bundle.. 12

6. Calculated deviation from the measured CHF versus mass flux for the KS-1 37-rod bundle.

7. Calculated deviation from the measured CHF versus inlet temperature for the KS-1 37-rod bundle

8. Calculated deviation from the measured CHF versus pressure for the KS-1 19-rod bundle.. 17

9. Calculated deviation from the measured CHF versus mass flux for the KS-1 19-rod bundle.

10. Calculated deviation from the measured CHF versus mass flux for the V-200 7-rod bundle.

11. Calculated deviation from the measured CHF versus inlet temperature for the V-200

7-rod bundle.

12. Calculated deviation from the measured CHF versus pressure for the three experiments..... 22

13. Calculated deviation from the measured CHF versus mass flux for the three experiments... 22

14. Calculated deviation from the measured $\mathrm{CHF}$ versus measured $\mathrm{CHF}$ for the three experiments.

\section{TABLES}

1. Base case calculations for the KS-1 37-rod bundle tests. 11

2. Base case calculations for the KS-1 19-rod bundle tests. 15

3. Base case calculations for the V-200 7-rod bundle tests. 


\section{ACRONYMS}

CHF

INEEL

IPPE

RBMK

RRC KI

VVER critical heat flux

Idaho National Engineering and Environmental Laboratory

Institute of Physics and Power Engineering

boiling water-cooled, graphite-moderated reactor

Russian Research Center "Kurchatov Institute"

water-cooled, water-moderated energy reactor 


\section{RELAP5/MOD3.2 Assessment Using CHF Data from the KS-1 and V-200 Experiment Facilities}

\section{INTRODUCTION}

The RELAP5/MOD3.2 computer code is being investigated to determine its applicability for modeling transients in Soviet-designed reactors. Part of that investigation includes assessment of the code using experiment data. Such an assessment has been performed using data from the KS-1 facility at the Russian Research Center "Kurchatov Institute" (RRC KI) and the V-200 facility at the Institute of Physics and Power Engineering (IPPE).

This work has been undertaken as part of Joint Project \#6, "Verification of Software with Respect to VVER and RBMK Reactors," of the U.S. Department of Energy's International Nuclear Safety Program. Russian experts and scientists from the United States are collaborating in the code assessment process. The specific experiments being used for this study were separate effects critical heat flux (CHF) tests performed in two different facilities with three different rod bundles. These tests have been selected as VVER Standard Problem 7.

\subsection{Important Phenomena}

Reference 1 identifies the transient phenomena that are important for any code to be able to model well in order to provide confidence in the simulation of VVER transient behavior. As a compilation of separate effects tests, Standard Problem 7 addresses only one phenomenon, core thermal-hydraulics.

\subsection{Code Capability Determination}

Judgments regarding code fidelity were made based on the code/data comparisons presented in this report. These judgments were based on the application of a standardized, consistent, and qualitative set of criteria. The terminology of these criteria is defined below.

"Excellent agreement" applies when the code exhibits no deficiencies in modeling a given behavior. Major and minor phenomena and trends are correctly predicted. The calculated results are judged to agree closely with the data. The calculation will, with few exceptions, lie within the uncertainty bands of the data. The code may be used with confidence in similar applications. (The term "major phenomena" refers to the phenomena that influence key parameters such as fuel rod cladding temperature, pressure, differential pressure, mass flow rate, and mass distribution. Predicting major trends means that the prediction shows the significant features of the data. Significant features include the magnitude of a given parameter through the transient, slopes, and inflection points that mark significant changes in the parameter.)

"Reasonable agreement" applies when the code exhibits minor deficiencies. Overall, the code provides an acceptable prediction. All major trends and phenomena are correctly predicted. Differences between calculation and data are greater than deemed necessary for excellent agreement. The calculation will occasionally lie outside the uncertainty bands of the data. However, the correct conclusions about trends and phenomena would be reached if the code were used in similar 
applications. The code models and/or facility model noding should be reviewed to see if improvements can be made.

"Minimal agreement" applies when the code exhibits significant deficiencies. Overall, the code provides a prediction that is only conditionally acceptable. Some major trends or phenomena are not predicted correctly, and some calculated values lie considerably outside the uncertainty bands of the data. Incorrect conclusions about trends and phenomena may be reached if the code were used in similar applications, and an appropriate warning needs to be issued to users. Selected code models and/or facility model noding need to be reviewed, modified, and assessed before the code can be used with confidence in similar applications.

"Insufficient agreement" applies when the code exhibits major deficiencies. The code provides an unacceptable prediction of the test. Major trends are not predicted correctly. Most calculated values lie outside the uncertainty bands of the data. Incorrect conclusions about trends and phenomena are probable if the code is used in similar applications, and an appropriate warning needs to be issued to users. Selected code models and/or facility model noding need to be reviewed, modified, and assessed before the code can be used with confidence in similar applications.

Assessment findings of "excellent" or "reasonable" indicate that the code can model those phenomena acceptably.

Subsequent sections of the report present a description of the test facilities and experiments, the RELAP5 code and test facility input models, the assessment results, the conclusions reached in the assessment study, and references. 


\section{FACILITY AND TEST DESCRIPTION}

Data from tests using different size rod bundles in the KS-1 and V-200 experiment facilities were collected and used in VVER Standard Problem 7. All of the bundles had rods arranged in a hexagonal matrix, simulating the subchannels in a VVER core. The data selected for the standard problem were for pressures below $7 \mathrm{MPa}$, and represent conditions that might occur in the plant after the initial blowdown in a loss-of-coolant accident. The CHF that occurred in each of the experiments was dryout at the top of a heated channel. None of the tests had a CHF characterized by vapor blanketing of the heated surface with bulk subcooled liquid.

\subsection{Experiment Facilities}

\subsubsection{KS-1 Facility}

The KS-1 test facility, located at RRC KI, is a semi-integral single loop model of the VVER primary system. The facility includes models of the reactor vessel downcomer, lower plenum, core, upper plenum, and hot leg, and has horizontal steam generator tube bundle simulators with passive heat removal. The fuel assembly model for the core consists of electrically heated tubes with a diameter of $9 \mathrm{~mm}$ and a heated length of $2.5 \mathrm{~m}$. Forced or natural circulation flow of the coolant can be modeled.

Measurements available in the system are the rod simulator temperatures along the height and radius of the core, absolute and differential pressures across the downcomer, upper plenum and core, coolant temperatures at the core inlet, upper plenum inlet and downcomer, and voltage and current to the heater rods. Data were collected at a sampling frequency of about $2 \mathrm{~Hz}$.

For the CHF tests, most of the system was unimportant, so the core region essentially became a separate effects test. A large number of tests were conducted over many years. For this standard problem, tests from 19- and 37-rod bundle experiments were selected; these are referred to as 3/- and 4/-, respectively, in the Experiment Definition Report ${ }^{2}$. Figures 1 and 2 show these bundles. Both bundles had stainless steel heater rods with a 2.5 -m heated length. In the 37-rod bundle, the center rod was unheated. Both bundles also had uniform axial and radial power profiles. Each bundle was surrounded by a hexagonal wall, but no information was provided on the wall thickness, material, or insulation.

\subsubsection{V-200 Facility}

The V-200 test facility is designed to study thermal hydraulic processes in circulation circuits and core components of VVER type power reactors for a wide range of fluid conditions. It is a high-pressure, forced circulation circuit made of stainless steel tubes with inside diameters up to $50 \mathrm{~mm}$, and includes several loops with replaceable experimental working sections. Three working sections are mounted in special boxes with heights up to $12 \mathrm{~m}$. Measurements available in the working section include the coolant and heater rod temperatures, power input to the heater rods, pressure, differential pressure across the test section, and coolant flow rate and mass levels.

For the CHF tests being investigated here, a 7-rod bundle was used. Shown in Figure 3, the bundle was surrounded by a wall that maintained the hexagonal/triangular subchannels. The stainless steel heater 


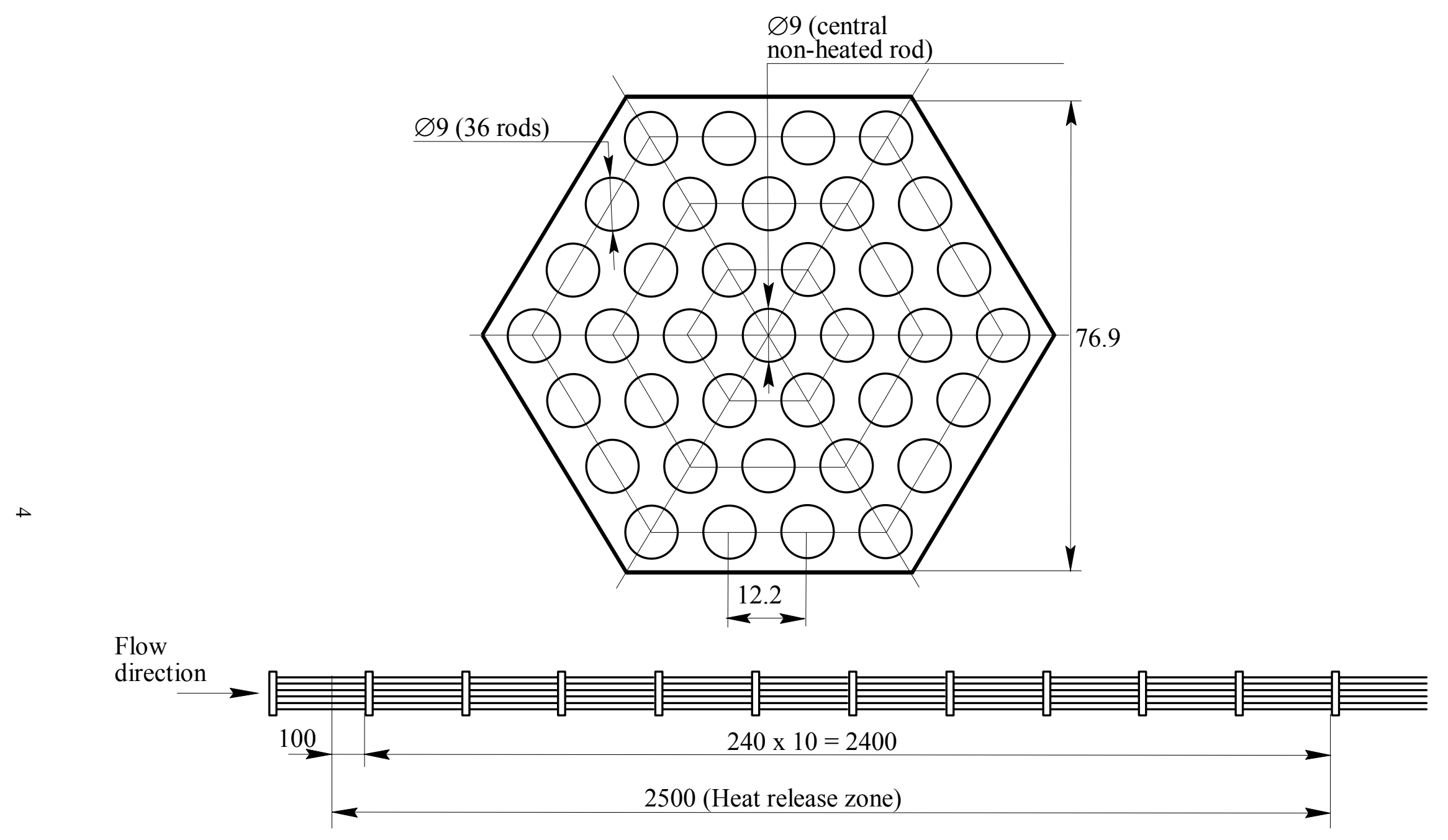

Figure 1. Geometric parameters of the KS-1 37-rod bundle. 

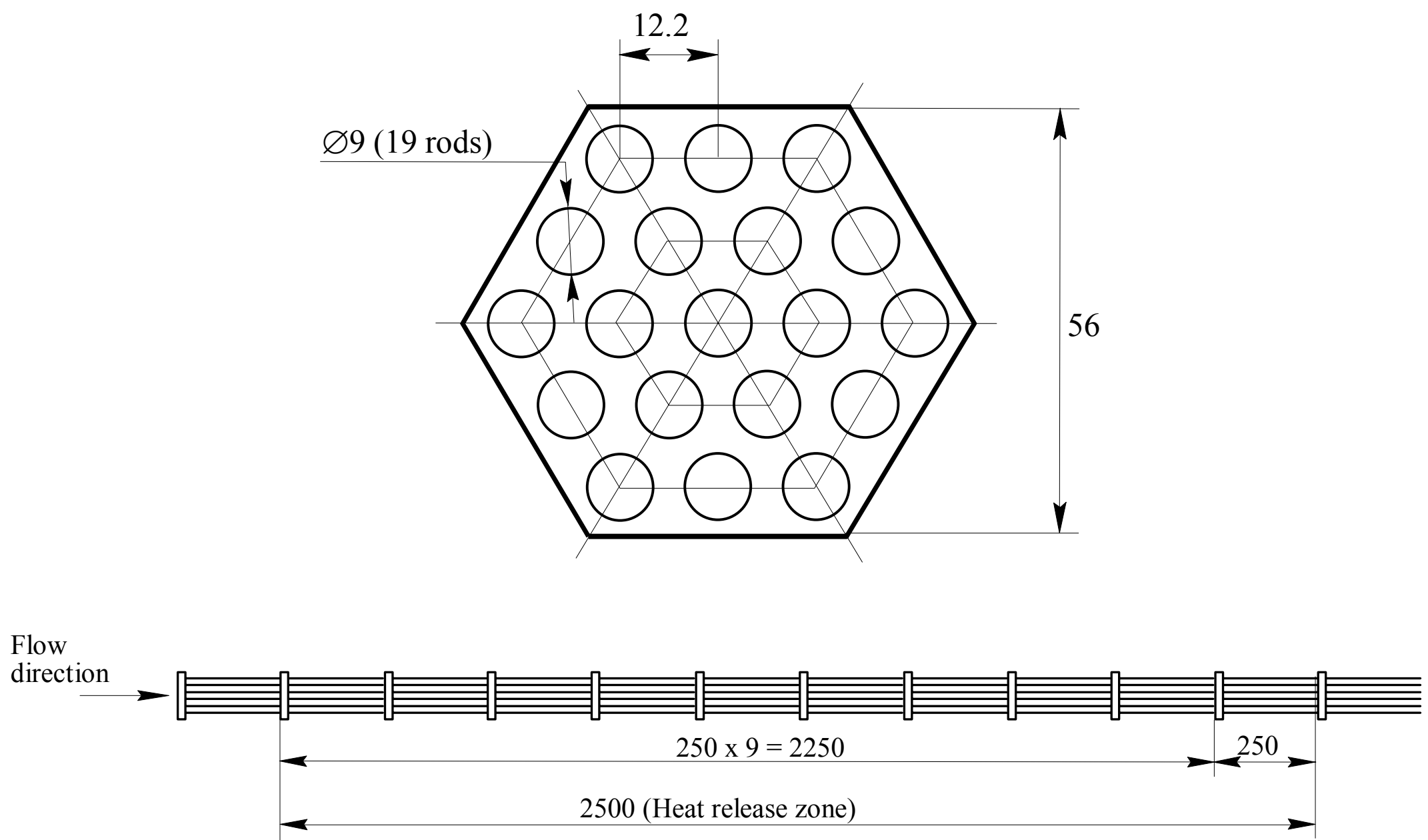

Figure 2. Geometric parameters of the KS-1 19-rod bundle. 


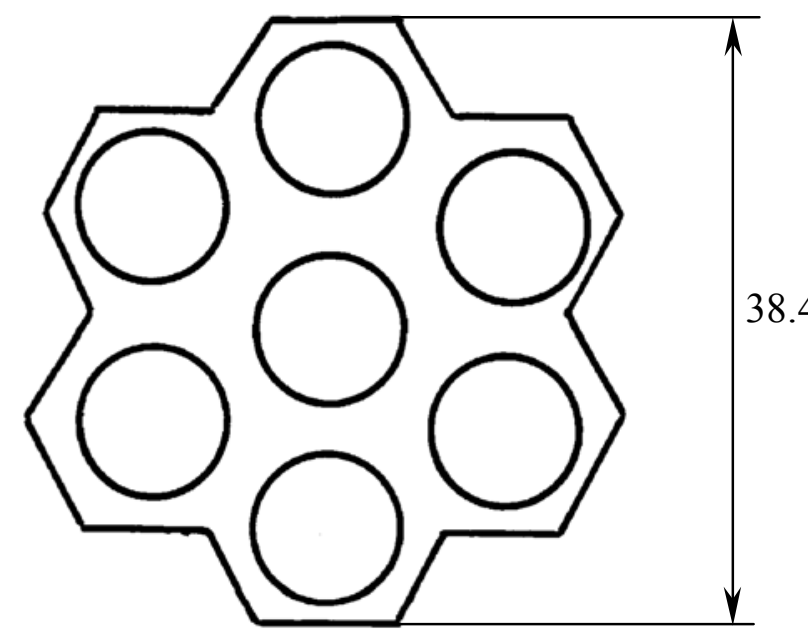

Figure 3. Cross section of the V-200 7-rod bundle.

rods had a heated length of $0.8 \mathrm{~m}$, and there was a uniform axial and radial power profile. There was no information available on the wall thickness, material, or insulation.

\subsection{Test Procedures}

Individual tests were started with a steady state condition at the desired pressure. The CHF was approached either by holding the flow rate constant and increasing the power or by holding the power constant and reducing the flow rate until elevated and increasing temperatures were measured on the heater rods.

Data provided in the Experiment Definition Report were the inlet flow rate, inlet temperature, inlet pressure and net heat flux at the time CHF occurred. There was no separate information on the power input or heat loss from the bundle, aside from an estimate of the errors in the power $(1.5 \%$ for KS-1, 2\% for V-200) and heat loss (4\% for KS-1) measurements. The stated uncertainty in the measured CHF in the KS-1 facility was $10 \%$; no uncertainty estimate was provided for the V-200 facility CHF measurement. 


\section{CODE AND INPUT MODEL DESCRIPTION}

The RELAP5/MOD3.2 code and input model used for the assessment calculations are described below. Also addressed are the initial and boundary conditions used for the transient calculations.

\subsection{RELAP5/MOD3.2}

The RELAP5/MOD3.2 computer code ${ }^{3}$ was developed at the Idaho National Engineering and Environmental Laboratory (INEEL) for use in analyzing transients in light water reactors. It can be used for simulating a wide variety of system transients of interest in reactor safety. The core, primary system, secondary system, feedwater train, and system controls can be simulated.

RELAP5/MOD3.2 uses a one-dimensional, two fluid, nonequilibrium, six equation hydrodynamic model with a simplified capability to treat multi-dimensional flows. This model provides continuity, momentum, and energy equations for both the liquid and the vapor phases within a control volume. The energy equation contains source terms which couple the hydrodynamic model to the heat structure conduction model by a convective heat transfer formulation. The code contains special process models for critical flow, abrupt area changes, branching, crossflow junctions, pumps, accumulators, valves, core neutronics, and control systems. A countercurrent flow limitation model can also be applied at vertical junctions. The reflood model does not work properly in this version of the code; that is not a concern for these experiments, in which there was no reflood in the bundles.

There is an error in the MOD3.2 version of the code that may impact the calculated CHF. The equilibrium quality, which is used in the CHF lookup tables, is calculated incorrectly. Some sensitivity calculations were performed with a more recent version of the RELAP5 code, MOD3.2.1.2, in which this error was corrected. It should be noted that correction of the equilibrium quality calculation was not the only difference in the code versions, and that other changes could also affect the calculated CHF (such as by changing the void profile in the core).

The code has been developed to run on a variety of computing platforms, from mainframes to personal computers. Configuration control is maintained on all versions of the code developed at the INEEL.

\subsection{RELAP5 Input Decks}

Similar input decks were used for all three sets of experiments. The basic nodalization is shown in Figure 4. A time-dependent volume and junction at the bottom of the bundle established the inlet flow and temperature. The single junction and time-dependent volume at the top of the bundle established the pressure. The bundle region was modeled with a pipe, with the number of volumes changing for each facility. A heat structure was used to model the heater rods, with a one-for-one axial nodalization correspondence with the hydraulic volumes. The outer wall of the bundle was not included in the base nodalization because the data provided were for the net heat flux, that is the power input minus the heat loss. 


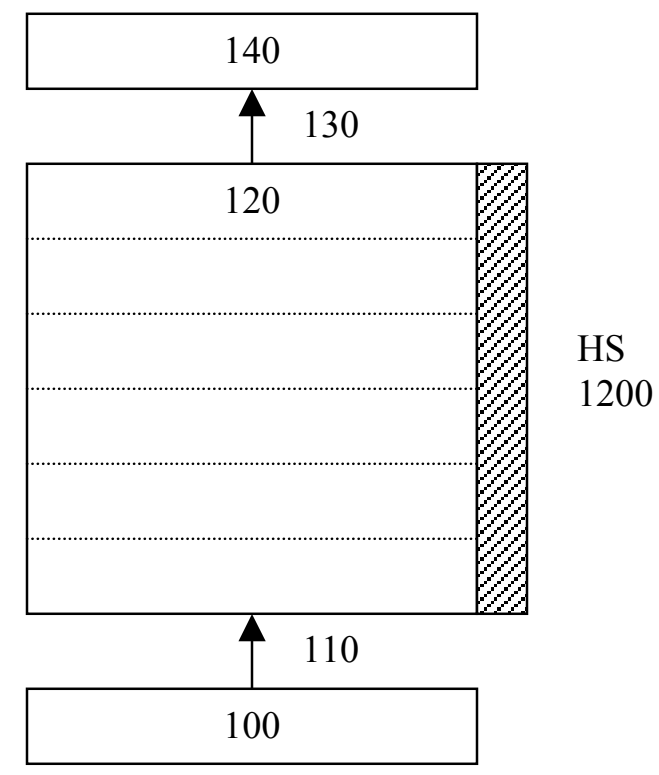

Figure 4. General RELAP5 nodalization of the experiments.

For the 37-rod bundle in the KS-1 facility, the pipe had twelve $0.24-\mathrm{m}$ high cells, with 11 of the cells spanning the heated length and an unheated volume at the top. The junctions between the cells of the pipe were aligned with the grid spacers.

For the 19-rod bundle in the KS-1 facility, the pipe had eleven $0.25-\mathrm{m}$ high cells, with 10 of the cells spanning the heated length and an unheated volume at the top. Again, the junctions between the cells were aligned with the grid spacers.

For the 7-rod bundle in the V-200 facility, the pipe had nine $0.10-\mathrm{m}$ high cells, with eight of the cells spanning the heated length and an unheated volume at the top. Grid spacers were located at the bottom, middle, and top of the bundle, so only the latter two were modeled in the pipe component.

For the sensitivity calculations investigating the effects of ambient heat losses, a second heat structure was added that represented the bundle wall. Several methods of modeling the heat loss were used: imposing a natural convection heat transfer coefficient and a sink temperature; using a constant-temperature volume on the outside of the bundle and allowing the code to calculate the heat transfer coefficient; and using a control system to set the heat loss as a fixed fraction of the heater rod power.

Control variables were used to track the critical heat flux in all of the calculations. For the sensitivity calculations in which the bundle wall was modeled, control variables were used to calculate the net heat flux into the fluid.

Default code options were used for all of the junctions and volumes, except for setting the bundle flag to 1 in the pipe; this enables the bundle interphase drag correlation. 


\subsection{Initial and Boundary Conditions}

Boundary conditions provided in the Experiment Definition Report were the inlet flow, temperature, and pressure. For each test point, the temperature and flow were set using the inlet time-dependent volume and junction, respectively. The pressure in the outlet time-dependent volume was set to provide the desired pressure at the inlet of the bundle. After the calculation, this pressure was checked. If the pressure was not at the desired value, the outlet pressure was adjusted, and the transient calculation re-run, until the desired inlet pressure was achieved.

In each calculation, the power was held constant for a short period to allow steady state conditions to be established, then the power input to the heater rods was steadily increased until CHF occurred. For the 37-rod bundle in the KS-1 facility, the power was increased from an initial value of $100 \mathrm{~kW}$ at a rate of $5.05 \mathrm{~kW} / \mathrm{s}$. For the 19-rod bundle in the KS-1 facility, the initial power was $10 \mathrm{~kW}$ and the rate of increase was $2.52 \mathrm{~kW} / \mathrm{s}$. For the 7 -rod bundle in the V-200 facility, the initial power was $10 \mathrm{~kW}$ and the rate of increase was $0.586 \mathrm{~kW} / \mathrm{s}$.

For the sensitivity calculations in which heat loss was modeled, the ambient temperature was assumed to be $300 \mathrm{~K}$.

\subsection{Calculation Information}

The RELAP5 calculations were run on a DEC AlphaStation computer. The semi-implicit solution scheme was used. The cpu time required to run the base case calculations ranged from 8 to $189 \mathrm{~s}$, with higher critical heat fluxes requiring longer calculations. The calculated mass error was very small, ranging from 0.0018 to $0.022 \%$ of the bundle coolant mass and indicating that an accurate numerical solution was being achieved. 


\section{CODE ASSESSMENT}

Assessment judgments were made for the high-ranked phenomenon believed to be addressed by this experiment, core heat transfer. The assessment definitions and criteria were listed in Section 1. The bulk of the discussion will address the base case calculations. Sensitivity calculations were also performed to investigate certain aspects of the base case that were of particular interest.

For statistical purposes, a deviation between the measured and calculated CHF values was determined for each test point. This deviation is defined in the Experiment Definition Report as

$$
\text { Deviation }(\%)=\frac{\mathrm{CHF}_{\text {measured }}-\mathrm{CHF}_{\text {calculated }}}{\mathrm{CHF}_{\text {measured }}} \times 100 \text {. }
$$

This definition yields negative deviations if the measured CHF is overpredicted and positive deviations if the CHF is underpredicted. Standard statistical parameters were also determined for each of the test series. The mean value is simply the average of the individual deviations, and the standard deviation is obtained using this formula:

$$
\sigma=\sqrt{\frac{\sum_{\mathrm{i}=1}^{\mathrm{n}}\left(\delta_{\mathrm{i}}-\bar{\delta}\right)^{2}}{\mathrm{n}-1}},
$$

where $\delta$ is the deviation, $\bar{\delta}$ is the mean deviation, and $\mathrm{n}$ is the number of points in the data set.

\subsection{KS-1 37-rod Bundle}

This was the largest bundle included in this standard problem. The test series included 63 data points at varying pressures, temperatures, and flow rates.

\subsubsection{Base Case}

The base case calculations were run with no outer wall heat structure on the bundle. For each case, the outlet pressure was adjusted until the pressure at the bottom of the bundle was close to that reported. All 63 test points were run; the results of these calculations are provided in Table 1 .

All of the measured CHF values were overpredicted by the code. Nearly all of the calculated values were overpredicted by 5-57\%; there was one outlier at $123 \%$. Figures 5-7 show the deviations as functions of pressure, mass flux, and temperature, respectively. The predictions were generally worse at low pressure and higher mass flux, with no apparent bias for the inlet temperature. 
Table 1. Base case calculations for the KS-1 37-rod bundle tests.

\begin{tabular}{|c|c|c|c|c|c|c|}
\hline Point & $\begin{array}{c}\text { Pressure } \\
\text { (bar) }\end{array}$ & $\begin{array}{c}\text { Mass flux } \\
\left(\mathrm{kg} / \mathrm{m}^{2} \mathrm{~s}\right)\end{array}$ & $\begin{array}{c}\text { Inlet } \\
\text { temperature } \\
\left({ }^{\circ} \mathrm{C}\right)\end{array}$ & $\begin{array}{c}\text { Measured } \\
\text { CHF } \\
\left(\mathrm{MW} / \mathrm{m}^{2}\right)\end{array}$ & $\begin{array}{c}\text { Calculated } \\
\text { CHF } \\
\left(\mathrm{MW} / \mathrm{m}^{2}\right) \\
\end{array}$ & $\begin{array}{c}\text { Deviation } \\
(\%)\end{array}$ \\
\hline 1 & 47.3 & 246 & 134 & 0.4920 & 0.5767 & -17.2 \\
\hline 2 & 49.1 & 406 & 134 & 0.7003 & 0.8825 & -26.0 \\
\hline 3 & 47.6 & 698 & 137 & 0.9659 & 1.3460 & -39.4 \\
\hline 4 & 48.1 & 259 & 97 & 0.5321 & 0.6455 & -21.3 \\
\hline 5 & 43.3 & 731 & 91 & 1.1003 & 1.4627 & -32.9 \\
\hline 6 & 42.4 & 359 & 63 & 0.7270 & 0.8939 & -23.0 \\
\hline 7 & 42.3 & 398 & 64 & 0.7529 & 0.9746 & -29.4 \\
\hline 8 & 48.8 & 621 & 62 & 1.1200 & 1.4021 & -25.2 \\
\hline 9 & 48.8 & 611 & 61 & 1.0901 & 1.3874 & -27.3 \\
\hline 10 & 30.0 & 295 & 109 & 0.5270 & 0.6914 & -31.2 \\
\hline 11 & 30.0 & 719 & 122 & 0.9353 & 1.3139 & -40.5 \\
\hline 12 & 28.2 & 718 & 90 & 0.9962 & 1.5604 & -56.6 \\
\hline 13 & 28.9 & 327 & 86 & 0.6052 & 0.7829 & -29.4 \\
\hline 14 & 29.0 & 277 & 85 & 0.5132 & 0.6778 & -32.1 \\
\hline 15 & 28.4 & 1169 & 96 & 1.3801 & 1.9182 & -39.0 \\
\hline 16 & 28.4 & 1499 & 102 & 1.5401 & 2.1682 & -40.8 \\
\hline 17 & 27.7 & 1290 & 76 & 1.4603 & 2.1087 & -44.4 \\
\hline 18 & 35.2 & 1259 & 128 & 1.3801 & 1.9368 & -40.3 \\
\hline 19 & 37.1 & 656 & 137 & 0.9121 & 1.2639 & -38.6 \\
\hline 20 & 36.3 & 1199 & 138 & 1.2901 & 1.8585 & -44.1 \\
\hline 21 & 36.3 & 1580 & 140 & 1.5102 & 2.1085 & -39.6 \\
\hline 22 & 36.3 & 693 & 157 & 0.9042 & 1.2554 & -38.8 \\
\hline 23 & 36.3 & 1159 & 161 & 1.1801 & 1.7403 & -47.5 \\
\hline 24 & 36.3 & 1330 & 159 & 1.2901 & 1.9401 & -50.4 \\
\hline 25 & 36.3 & 1489 & 161 & 1.3703 & 1.9456 & -42.0 \\
\hline 26 & 35.8 & 1650 & 158 & 1.4501 & 2.0578 & -41.9 \\
\hline 27 & 51.7 & 757 & 159 & 1.0202 & 1.3638 & -33.7 \\
\hline 28 & 48.5 & 1219 & 158 & 1.3200 & 1.8091 & -37.1 \\
\hline 29 & 47.6 & 1169 & 139 & 1.3601 & 1.8492 & -36.0 \\
\hline 30 & 46.5 & 1580 & 140 & 1.5904 & 2.1469 & -35.0 \\
\hline 31 & 46.5 & 1670 & 140 & 1.6403 & 2.1963 & -33.9 \\
\hline 32 & 48.8 & 684 & 97 & 1.0701 & 1.4063 & -31.4 \\
\hline 33 & 45.7 & 1110 & 101 & 1.4100 & 1.9484 & -38.2 \\
\hline 34 & 44.9 & 1290 & 101 & 1.5503 & 2.1123 & -36.3 \\
\hline 35 & 52.1 & 240 & 172 & 0.4610 & 0.5227 & -13.4 \\
\hline 36 & 53.4 & 220 & 152 & 0.4350 & 0.5038 & -15.8 \\
\hline 37 & 55.9 & 682 & 192 & 0.9392 & 1.1800 & -25.6 \\
\hline 38 & 52.4 & 261 & 208 & 0.4429 & 0.5205 & -17.5 \\
\hline 39 & 54.3 & 375 & 64 & 0.8280 & 0.9262 & -11.6 \\
\hline 40 & 51.2 & 232 & 65 & 0.5392 & 0.6169 & -14.4 \\
\hline 41 & 57.2 & 580 & 96 & 1.0602 & 1.2501 & -17.9 \\
\hline 42 & 55.9 & 264 & 96 & 0.5851 & 0.6612 & -13.0 \\
\hline 43 & 59.5 & 690 & 113 & 1.1302 & 1.3682 & -21.1 \\
\hline 44 & 60.6 & 338 & 132 & 0.6700 & 0.7603 & -13.5 \\
\hline
\end{tabular}


Table 1. (continued).

\begin{tabular}{|c|c|c|c|c|c|c|}
\hline Point & $\begin{array}{c}\text { Pressure } \\
(\text { bar })\end{array}$ & $\begin{array}{c}\text { Mass flux } \\
\left(\mathrm{kg} / \mathrm{m}^{2} \mathrm{~s}\right)\end{array}$ & $\begin{array}{c}\text { Inlet } \\
\text { temperature } \\
\left({ }^{\circ} \mathrm{C}\right)\end{array}$ & $\begin{array}{c}\text { Measured } \\
\mathrm{CHF} \\
\left(\mathrm{MW} / \mathrm{m}^{2}\right)\end{array}$ & $\begin{array}{c}\text { Calculated } \\
\mathrm{CHF} \\
\left(\mathrm{MW} / \mathrm{m}^{2}\right)\end{array}$ & $\begin{array}{c}\text { Deviation } \\
(\%)\end{array}$ \\
\hline 45 & 38.2 & 276 & 171 & 0.4790 & 0.5852 & -22.2 \\
\hline 46 & 61.9 & 526 & 136 & 0.9282 & 1.0778 & -16.1 \\
\hline 47 & 57.5 & 288 & 190 & 0.5380 & 0.5898 & -9.63 \\
\hline 48 & 59.0 & 697 & 201 & 0.8622 & 1.1720 & -35.9 \\
\hline 49 & 57.5 & 252 & 208 & 0.4790 & 0.5053 & -5.49 \\
\hline 50 & 57.2 & 263 & 241 & 0.4500 & 0.4822 & -7.16 \\
\hline 51 & 57.6 & 271 & 260 & 0.4452 & 0.4688 & -5.30 \\
\hline 52 & 55.0 & 336 & 257 & 0.4932 & 0.5701 & -15.6 \\
\hline 53 & 54.2 & 345 & 236 & 0.5211 & 0.6190 & -18.8 \\
\hline 54 & 57.8 & 414 & 257 & 0.5431 & 0.6837 & -25.9 \\
\hline 55 & 58.4 & 545 & 256 & 0.6441 & 0.8433 & -30.9 \\
\hline 56 & 59.0 & 641 & 240 & 0.7573 & 1.0053 & -32.7 \\
\hline 57 & 38.0 & 270 & 199 & 0.5050 & 0.5397 & -6.88 \\
\hline 58 & 39.6 & 640 & 237 & 0.6732 & 1.0093 & -49.9 \\
\hline 59 & 37.9 & 271 & 236 & 0.4221 & 0.4939 & -17.0 \\
\hline 60 & 21.8 & 291 & 176 & 0.4169 & 0.5886 & -41.2 \\
\hline 61 & 22.2 & 404 & 172 & 0.5199 & 1.1605 & -123.2 \\
\hline 62 & 21.7 & 353 & 150 & 0.5191 & 0.7293 & -40.5 \\
\hline 63 & 21.5 & 261 & 147 & 0.4649 & 0.5685 & -22.3 \\
\hline
\end{tabular}

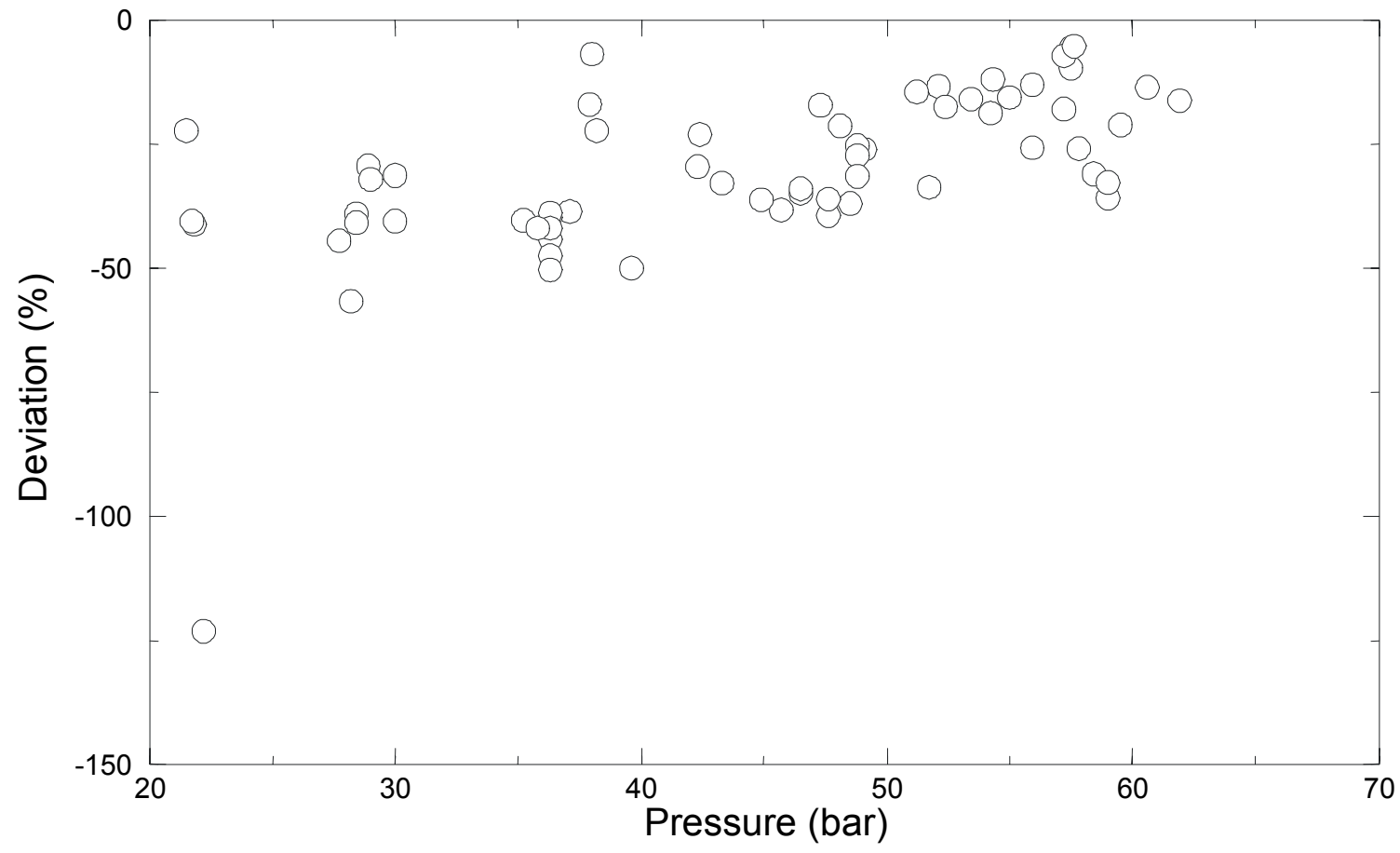

Figure 5. Calculated deviation from the measured CHF versus pressure for the KS-1 37-rod bundle. 


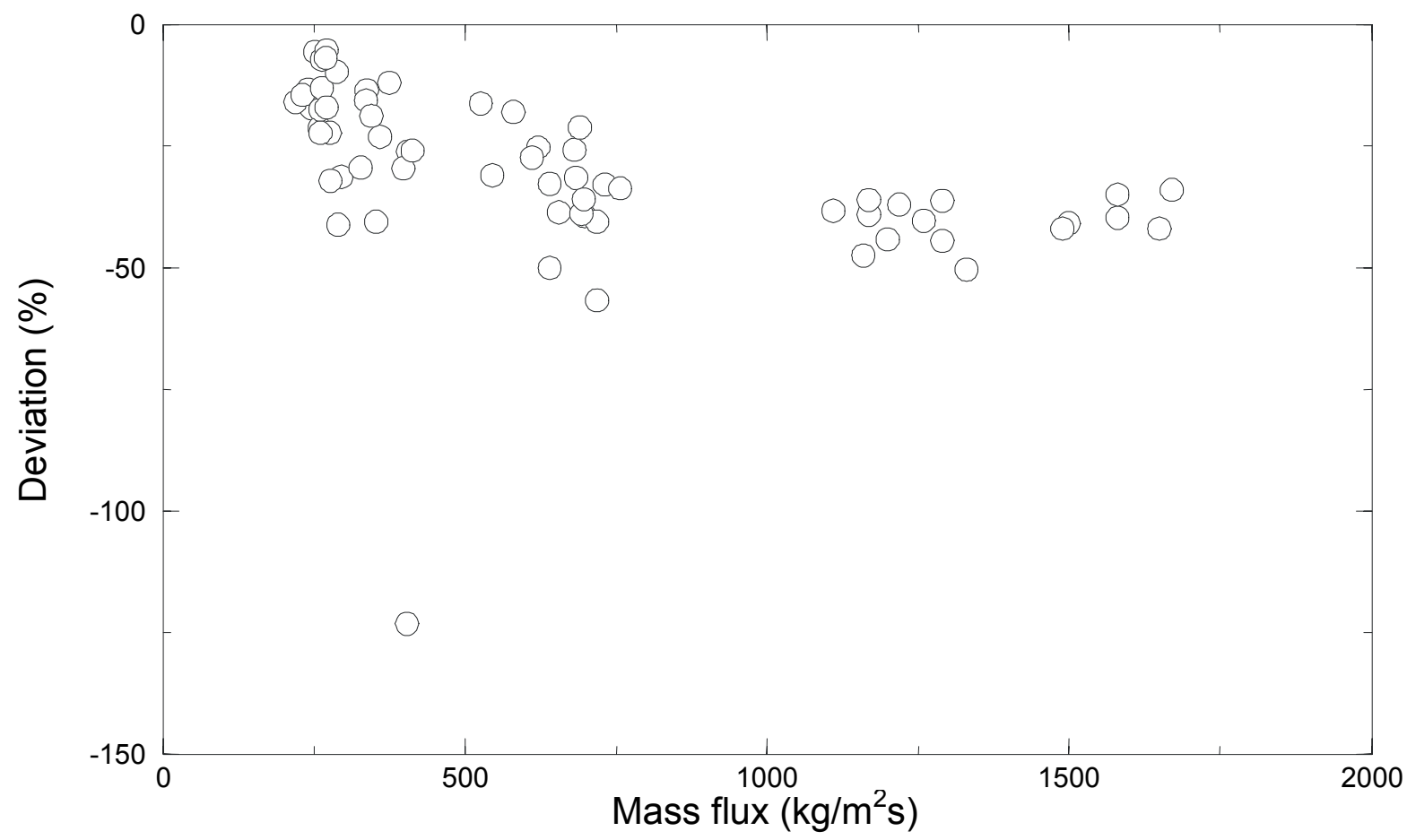

Figure 6. Calculated deviation from the measured CHF versus mass flux for the KS-1 37-rod bundle.

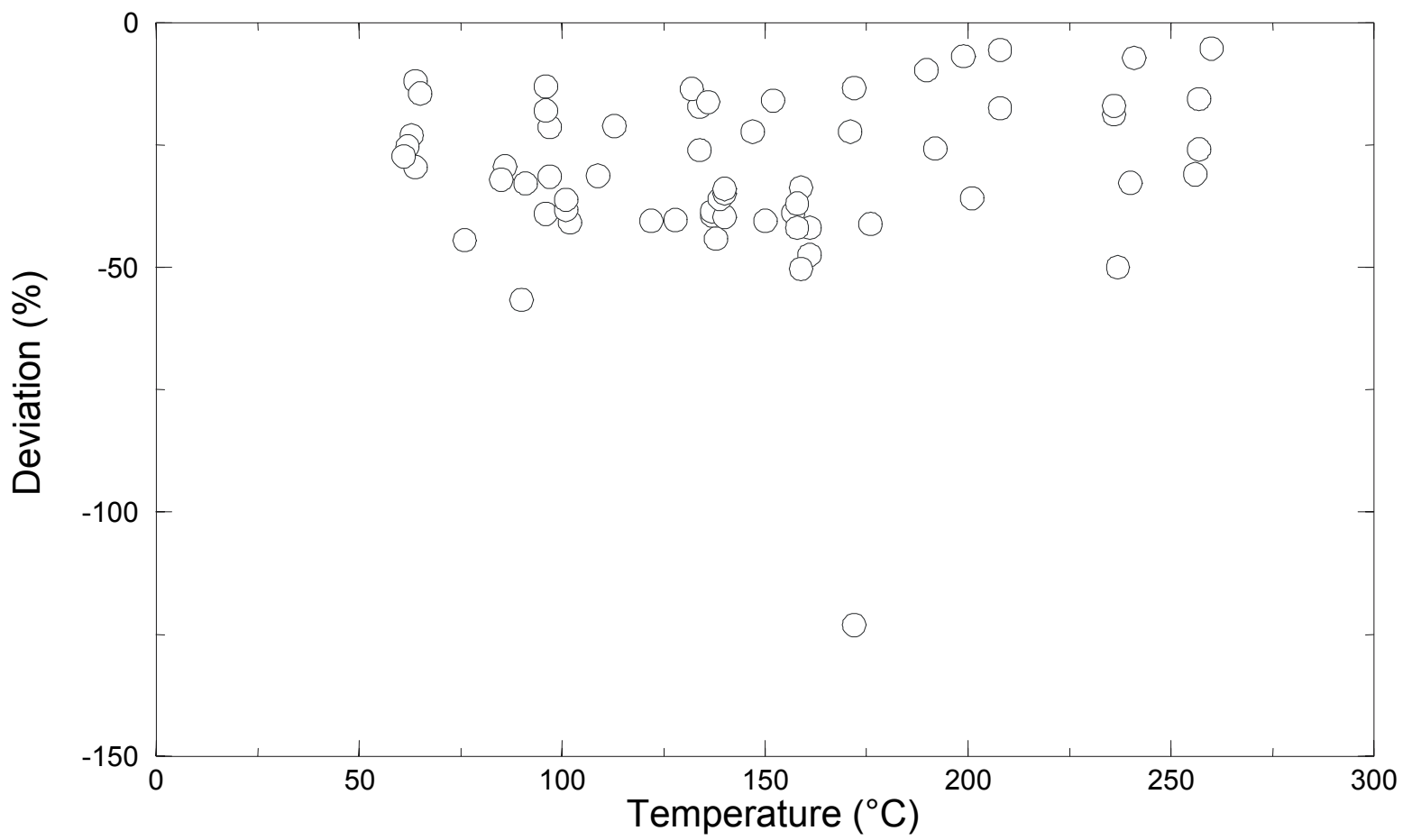

Figure 7. Calculated deviation from the measured CHF versus inlet temperature for the KS-1 37-rod bundle. 
The mean deviation for these calculations was $-30.3 \%$, with a standard deviation of $17.2 \%$. If point number 61 is removed from the sample, the mean is $-28.8 \%$ with a standard deviation of $12.5 \%$. With a $10 \%$ uncertainty in the measured CHF, the code calculations are judged to be in minimal agreement with these test data.

\subsubsection{Sensitivity Calculations}

Based on the results of the base case calculations, several parameters were investigated to determine the reasons for the overprediction of the CHF. Not all of the data points were used in these studies; those selected were points $1,9,17,25,33,41,49$, and 57. These points include representative variations in the pressure, mass flux, and temperature such that the general effect of each sensitivity parameter change could be assessed.

Many of the sensitivity calculations resulted in little change from the base case. Those that resulted in less than a $1 \%$ change in the calculated CHF were

- modeling an insulated bundle wall with an assumed external natural convection heat transfer coefficient of $15 \mathrm{~W} / \mathrm{m}^{2} \mathrm{~K}$

- modeling an uninsulated bundle wall with an assumed external natural convection heat transfer coefficient of $15 \mathrm{~W} / \mathrm{m}^{2} \mathrm{~K}$

- modeling an uninsulated bundle wall with a code-calculated external natural convection heat transfer coefficient

- modeling the unheated center rod

- reducing the heatup rate by a factor of 3

- increasing the initial power by a factor of 10

- adding a grid spacer loss coefficient of 0.5 at each of the junctions.

Doubling the number of axial nodes in the pipe reduced the predicted CHF by $1-4 \%$, with smaller changes at lower heat fluxes and a larger effect at higher heat fluxes.

Another sensitivity study investigated the impact of uncertainties in the boundary conditions. Increasing the inlet mass flux by $5 \%$ increased the calculated CHF by $2-5 \%$, with the larger effect seen at lower flow rates. Similarly, reducing the inlet mass flux by $5 \%$ lowered the predicted CHF by $2-5 \%$, again with the larger effect at the lower flow rates.

Performing the calculation with a newer version of the code, MOD3.2.1.2, had no effect on the sensitivity cases with CHF values above $1 \mathrm{MW} / \mathrm{m}^{2}$, while it reduced the CHF prediction by 1$3 \%$ for the lower flux cases.

A final set of sensitivity calculations was run investigating the effect of ambient heat loss. The Experiment Definition Report, although it did not contain values for these heat losses, estimated the uncertainty in the heat loss to be $4 \%$. This indicates that the heat loss might be within one or two orders of magnitude of the heat input to the bundle. The earlier heat loss sensitivity calculations, in which the heat transfer coefficient on the outside of the wall was either user-specified or code-calculated, had maximum heat losses that were several orders of magnitude lower than the power input. For these sensitivity calculations, nominal heat losses of $1,5,10$ and $16 \%$ of the bundle power input were imposed on the model. These cases resulted in average reductions in the predicted $\mathrm{CHF}$ of $1,4,6$, and $8 \%$, respectively. 
None of the parameters altered made a significant enough difference in the calculated CHF to change the overall conclusion that the code is consistently overpredicting the measured CHF.

\subsection{KS-1 19-rod Bundle}

Fifty four tests were run using the 19-rod bundle in the KS-1 test facility, varying the pressure, temperature, and mass flux.

\subsubsection{Base Case}

All 54 test points were calculated. The results from the calculations are provided in Table 2. The mean deviation for these calculations was $-48.1 \%$, with a standard deviation of $34.0 \%$. These calculations had larger deviations than the 37-rod bundle tests, because there were more points at low pressure, where the code is overpredicting the CHF by a larger margin than at high pressures. This is illustrated in Figure 8, which shows the calculated deviation as a function of the bundle pressure. The larger deviations are seen at lower pressures. There was also a bias in the calculations for the mass flux, with greater deviations at lower mass flux rates, as shown in Figure 9. The large spread in the deviations at a mass flux of about $800 \mathrm{~kg} / \mathrm{m}^{2} \mathrm{~s}$ indicates that the pressure effect on the CHF calculation is greater than the mass flux effect. As for the 37-rod bundle, there was no apparent bias in the calculated heat flux based on the inlet fluid temperature.

Table 2. Base case calculations for the KS-1 19-rod bundle tests.

\begin{tabular}{|c|c|c|c|c|c|c|}
\hline Point & $\begin{array}{c}\text { Pressure } \\
(\mathrm{bar})\end{array}$ & $\begin{array}{c}\text { Mass flux } \\
\left(\mathrm{kg} / \mathrm{m}^{2} \mathrm{~s}\right)\end{array}$ & $\begin{array}{c}\text { Inlet } \\
\text { temperature } \\
\left({ }^{\circ} \mathrm{C}\right)\end{array}$ & $\begin{array}{c}\text { Measured } \\
\mathrm{CHF} \\
\left(\mathrm{MW} / \mathrm{m}^{2}\right)\end{array}$ & $\begin{array}{c}\text { Calculated } \\
\text { CHF } \\
\left(\mathrm{MW} / \mathrm{m}^{2}\right)\end{array}$ & $\begin{array}{c}\text { Deviation } \\
(\%)\end{array}$ \\
\hline 1 & 68.2 & 813 & 194 & 0.9903 & 1.3107 & -32.4 \\
\hline 2 & 68.2 & 1080 & 200 & 1.1496 & 1.4660 & -27.5 \\
\hline 3 & 66.9 & 1160 & 207 & 1.1697 & 1.4948 & -27.8 \\
\hline 4 & 69.2 & 790 & 210 & 0.9300 & 1.2519 & -34.6 \\
\hline 5 & 70.0 & 1210 & 219 & 1.1400 & 1.4495 & -27.1 \\
\hline 6 & 37.1 & 749 & 209 & 0.8257 & 1.2022 & -45.6 \\
\hline 7 & 35.3 & 748 & 49 & 1.1913 & 1.6363 & -37.3 \\
\hline 8 & 69.2 & 480 & 241 & 0.6289 & 0.8136 & -29.4 \\
\hline 9 & 69.2 & 511 & 209 & 0.6920 & 0.9228 & -33.4 \\
\hline 10 & 69.2 & 695 & 240 & 0.7937 & 1.0781 & -35.8 \\
\hline 11 & 70.0 & 460 & 286 & 0.5020 & 0.6942 & -38.3 \\
\hline 12 & 70.0 & 428 & 279 & 0.5160 & 0.6693 & -29.7 \\
\hline 13 & 70.0 & 892 & 282 & 0.7781 & 1.0762 & -38.3 \\
\hline 14 & 69.4 & 1657 & 226 & 1.3596 & 1.6058 & -18.1 \\
\hline 15 & 69.2 & 1199 & 219 & 1.1980 & 1.4501 & -21.0 \\
\hline 16 & 68.5 & 1268 & 244 & 1.1459 & 1.3738 & -19.9 \\
\hline 17 & 68.0 & 1446 & 243 & 1.2263 & 1.4419 & -17.6 \\
\hline 18 & 68.5 & 1615 & 242 & 1.2926 & 1.5019 & -16.2 \\
\hline 19 & 68.5 & 1864 & 244 & 1.3559 & 1.5769 & -16.3 \\
\hline 20 & 68.5 & 2188 & 245 & 1.4259 & 1.6765 & -17.6 \\
\hline 21 & 68.5 & 2280 & 245 & 1.4490 & 1.7077 & -17.9 \\
\hline & & & & & & \\
\hline
\end{tabular}


Table 2. (continued).

\begin{tabular}{|c|c|c|c|c|c|c|}
\hline Point & $\begin{array}{c}\text { Pressure } \\
(\text { bar })\end{array}$ & $\begin{array}{c}\text { Mass flux } \\
\left(\mathrm{kg} / \mathrm{m}^{2} \mathrm{~s}\right)\end{array}$ & $\begin{array}{c}\text { Inlet } \\
\text { temperature } \\
\left({ }^{\circ} \mathrm{C}\right)\end{array}$ & $\begin{array}{c}\text { Measured } \\
\mathrm{CHF} \\
\left(\mathrm{MW} / \mathrm{m}^{2}\right)\end{array}$ & $\begin{array}{c}\text { Calculated } \\
\mathrm{CHF} \\
\left(\mathrm{MW} / \mathrm{m}^{2}\right)\end{array}$ & $\begin{array}{c}\text { Deviation } \\
(\%)\end{array}$ \\
\hline 22 & 67.7 & 2418 & 246 & 1.4683 & 1.7488 & -19.1 \\
\hline 23 & 68.5 & 2560 & 245 & 1.5152 & 1.8078 & -19.3 \\
\hline 24 & 68.5 & 2794 & 245 & 1.5629 & 1.8935 & -21.2 \\
\hline 25 & 51.2 & 1090 & 243 & 1.0729 & 1.4146 & -31.8 \\
\hline 26 & 51.2 & 1700 & 240 & 1.2799 & 1.6862 & -31.7 \\
\hline 27 & 52.8 & 2339 & 242 & 1.4266 & 1.8443 & -29.8 \\
\hline 28 & 53.0 & 2678 & 241 & 1.4988 & 1.9430 & -29.6 \\
\hline 29 & 50.7 & 2391 & 222 & 1.5778 & 2.0250 & -28.3 \\
\hline 30 & 51.5 & 2778 & 204 & 1.8153 & 2.3274 & -28.2 \\
\hline 31 & 50.7 & 1847 & 203 & 1.5122 & 1.9411 & -28.4 \\
\hline 32 & 49.9 & 1076 & 203 & 1.2040 & 1.5550 & -29.2 \\
\hline 33 & 51.2 & 1752 & 185 & 1.6083 & 2.0034 & -24.6 \\
\hline 34 & 49.8 & 2127 & 181 & 1.7379 & 2.2141 & -27.4 \\
\hline 35 & 50.4 & 2675 & 181 & 1.9099 & 2.4973 & -30.8 \\
\hline 36 & 49.0 & 2852 & 180 & 2.0930 & 2.6079 & -24.6 \\
\hline 37 & 10.1 & 776 & 140.4 & 0.5594 & 1.0484 & -87.4 \\
\hline 38 & 8.0 & 765 & 151.1 & 0.4838 & 0.8705 & -79.9 \\
\hline 39 & 7.8 & 758 & 154.4 & 0.4780 & 0.8733 & -82.7 \\
\hline 40 & 12.5 & 773 & 185.4 & 0.4970 & 1.1041 & -122.2 \\
\hline 41 & 17.3 & 812 & 174.2 & 0.5440 & 1.3225 & -143.1 \\
\hline 42 & 11.5 & 801 & 98 & 0.7040 & 1.3727 & -95.0 \\
\hline 43 & 19.0 & 723 & 48.3 & 0.8630 & 1.6690 & -93.4 \\
\hline 44 & 17.0 & 748 & 48.5 & 0.8302 & 1.6712 & -101.3 \\
\hline 45 & 17.9 & 733 & 68.5 & 0.8317 & 1.6062 & -93.1 \\
\hline 46 & 17.2 & 744 & 80.5 & 0.7893 & 1.5700 & -98.9 \\
\hline 47 & 15.7 & 755 & 129.3 & 0.6289 & 1.3888 & -120.8 \\
\hline 48 & 28.3 & 713 & 164.6 & 0.7040 & 1.3564 & -92.7 \\
\hline 49 & 20.7 & 784 & 193.3 & 0.5810 & 1.1452 & -97.1 \\
\hline 50 & 25.3 & 784 & 206.1 & 0.6220 & 1.1569 & -86.0 \\
\hline 51 & 25.3 & 791 & 210.3 & 0.5810 & 1.1506 & -98.0 \\
\hline 52 & 44.9 & 749 & 203.3 & 0.9121 & 1.2649 & -38.7 \\
\hline 53 & 43.4 & 749 & 221.7 & 0.8369 & 1.2037 & -43.8 \\
\hline 54 & 33.4 & 749 & 51.4 & 1.1913 & 1.6271 & -36.6 \\
\hline & & & & & & \\
\hline
\end{tabular}

\subsubsection{Sensitivity Calculations}

The only sensitivity calculation run for these tests was with the MOD3.2.1.2 version of the code. Seven of the points were recalculated, with the selection providing a representative range of pressure and mass flux values. The only case in which the predicted CHF changed by more than $1 \%$ was for a low pressure case (point 41 ), where the deviation changed from $-143.1 \%$ to $-112.0 \%$. 


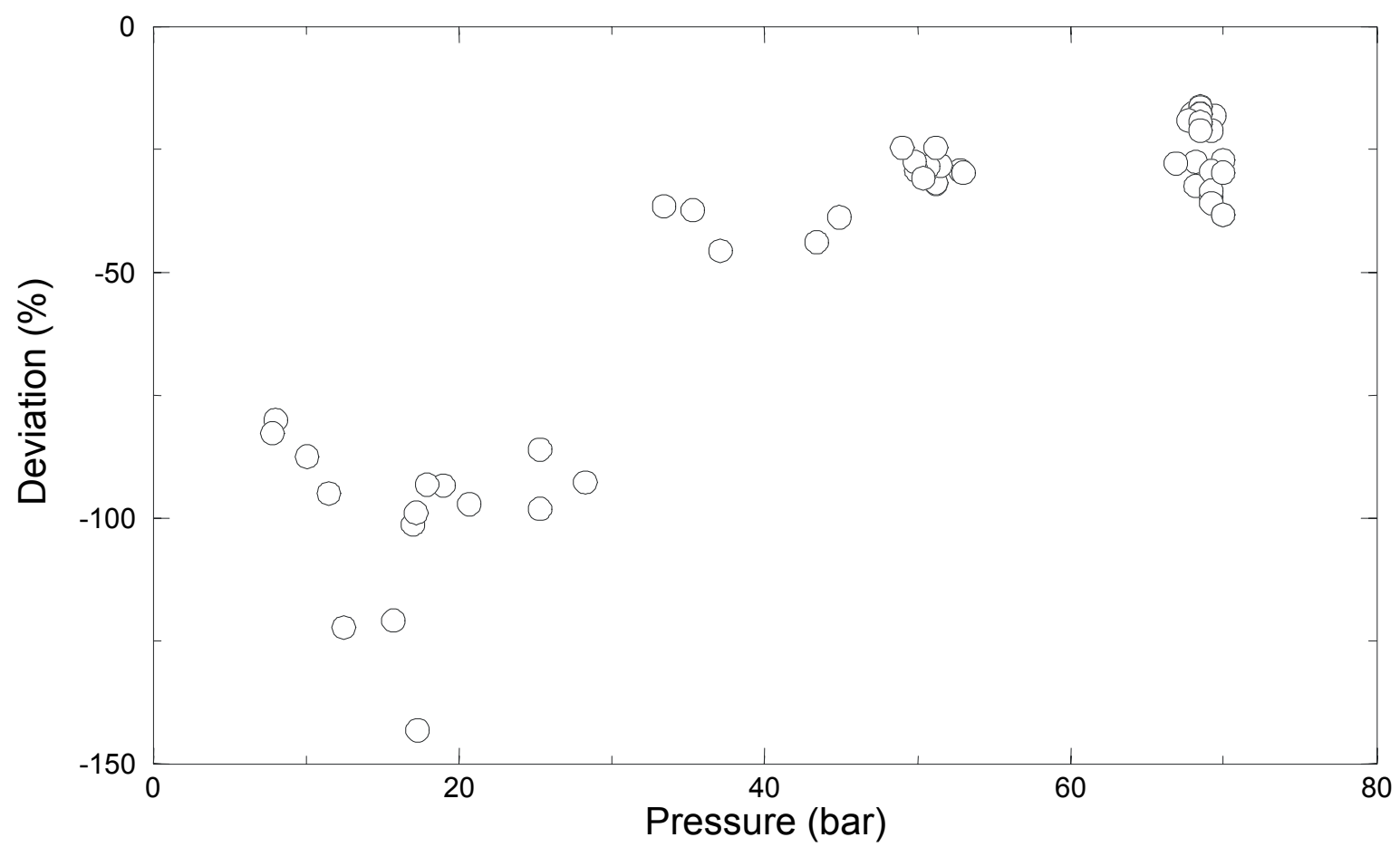

Figure 8. Calculated deviation from the measured CHF versus pressure for the KS-1 19-rod bundle.

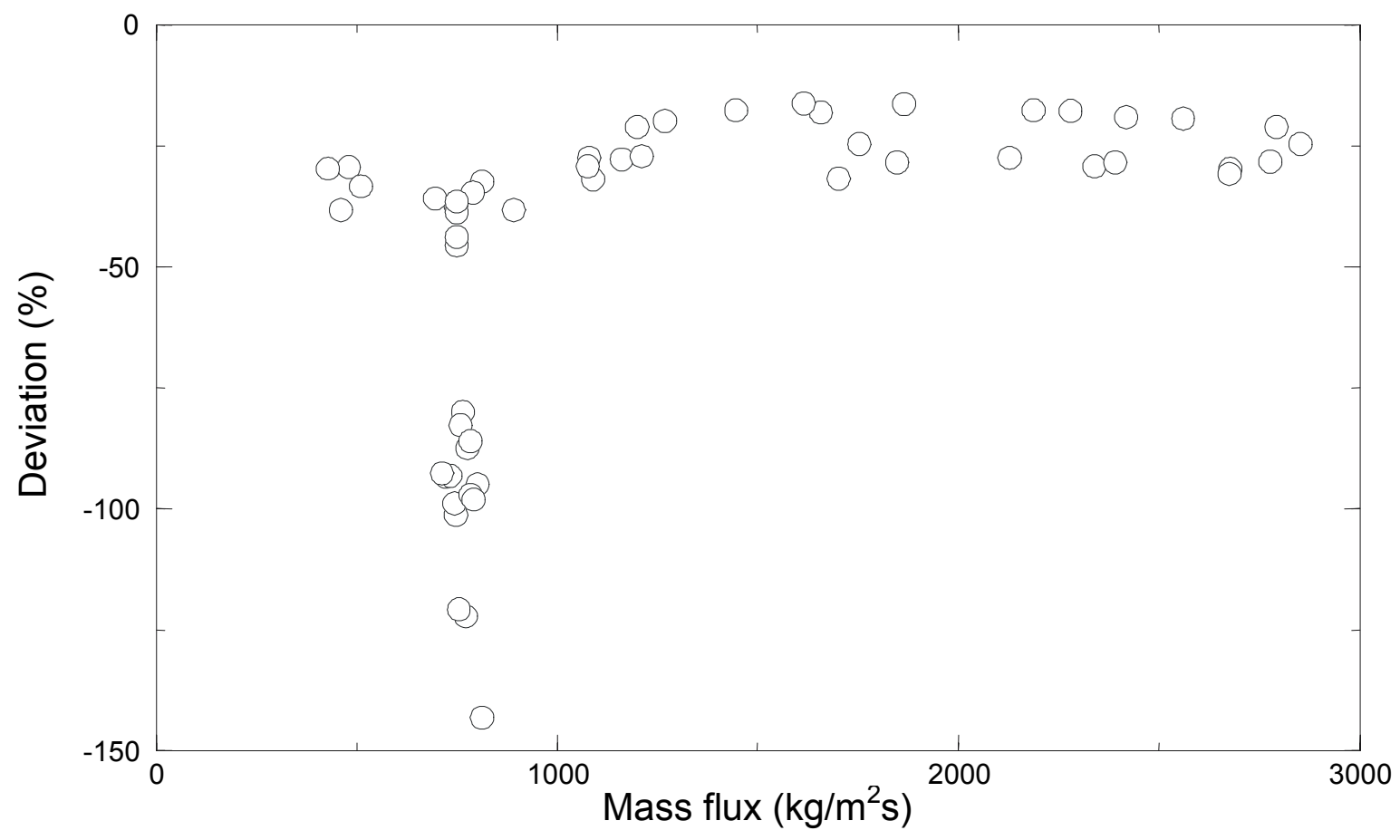

Figure 9. Calculated deviation from the measured CHF versus mass flux for the KS-1 19-rod bundle. 


\subsection{V-200 7-rod Bundle Tests}

The 25 test points selected from experiments in the V-200 facility at IPPE were all run at the same pressure. There were two mass fluxes used, with a wide range of inlet temperatures. Base case and sensitivity calculations were run for these experiments.

\subsubsection{Base Case}

The base case calculations neglected any heat structures besides the heater rods. Results from these calculations are provided in Table 3.

The mean deviation for these calculations was $-15.0 \%$, with a standard deviation of $9.6 \%$. There is a noticeable effect of mass flux on the predicted CHF, with the overprediction being greater at higher mass fluxes. This is illustrated in Figure 10. There appears to be a small effect of inlet temperature on the calculated CHF, as shown in Figure 11. For the higher mass flux cases (larger absolute deviations), the deviation increases with increasing temperature. For the

Table 3. Base case calculations for the V-200 7-rod bundle tests.

\begin{tabular}{|c|c|c|c|c|c|c|}
\hline Point & $\begin{array}{c}\text { Pressure } \\
(\text { bar })\end{array}$ & $\begin{array}{c}\text { Mass flux } \\
\left(\mathrm{kg} / \mathrm{m}^{2} \mathrm{~s}\right)\end{array}$ & $\begin{array}{c}\text { Inlet } \\
\text { temperature } \\
\left({ }^{\circ} \mathrm{C}\right)\end{array}$ & $\begin{array}{c}\text { Measured } \\
\mathrm{CHF} \\
\left(\mathrm{MW} / \mathrm{m}^{2}\right)\end{array}$ & $\begin{array}{c}\text { Calculated } \\
\text { CHF } \\
\left(\mathrm{MW} / \mathrm{m}^{2}\right)\end{array}$ & $\begin{array}{c}\text { Deviation } \\
(\%)\end{array}$ \\
\hline 1 & 68 & 207.4 & 73 & 1.379 & 1.4453 & -4.81 \\
\hline 2 & 68 & 207.4 & 74 & 1.334 & 1.4428 & -8.16 \\
\hline 3 & 68 & 209.5 & 75 & 1.334 & 1.453 & -8.92 \\
\hline 4 & 68 & 219.7 & 98 & 1.334 & 1.4574 & -9.25 \\
\hline 5 & 68 & 217.6 & 99 & 1.319 & 1.4427 & -9.38 \\
\hline 6 & 68 & 207.4 & 131 & 1.205 & 1.3022 & -8.07 \\
\hline 7 & 68 & 207.4 & 134 & 1.220 & 1.2946 & -6.11 \\
\hline 8 & 68 & 212.0 & 159 & 1.152 & 1.2557 & -9.00 \\
\hline 9 & 68 & 212.0 & 186 & 1.106 & 1.185 & -7.14 \\
\hline 10 & 68 & 212.0 & 187 & 1.106 & 1.1824 & -6.91 \\
\hline 11 & 68 & 207.4 & 215 & 1.046 & 1.084 & -3.63 \\
\hline 12 & 68 & 209.5 & 216 & 1.038 & 1.0908 & -5.07 \\
\hline 13 & 68 & 209.5 & 246 & 0.955 & 1.0144 & -6.22 \\
\hline 14 & 68 & 204.6 & 259 & 0.917 & 0.9589 & -4.57 \\
\hline 15 & 68 & 353.1 & 74 & 1.796 & 2.1641 & -20.5 \\
\hline 16 & 68 & 353.1 & 103 & 1.705 & 2.0743 & -21.7 \\
\hline 17 & 68 & 347.1 & 105 & 1.675 & 2.0542 & -22.6 \\
\hline 18 & 68 & 353.1 & 139 & 1.576 & 1.9609 & -24.4 \\
\hline 19 & 68 & 353.1 & 140 & 1.607 & 1.9577 & -21.8 \\
\hline 20 & 68 & 348.8 & 176 & 1.425 & 1.8181 & -27.6 \\
\hline 21 & 68 & 353.1 & 178 & 1.440 & 1.8229 & -26.6 \\
\hline 22 & 68 & 349.2 & 204 & 1.326 & 1.7069 & -28.7 \\
\hline 23 & 68 & 342.9 & 233 & 1.243 & 1.568 & -26.1 \\
\hline 24 & 68 & 347.1 & 235 & 1.212 & 1.5713 & -29.6 \\
\hline 25 & 68 & 348.8 & 251 & 1.175 & 1.5053 & -28.1 \\
\hline
\end{tabular}




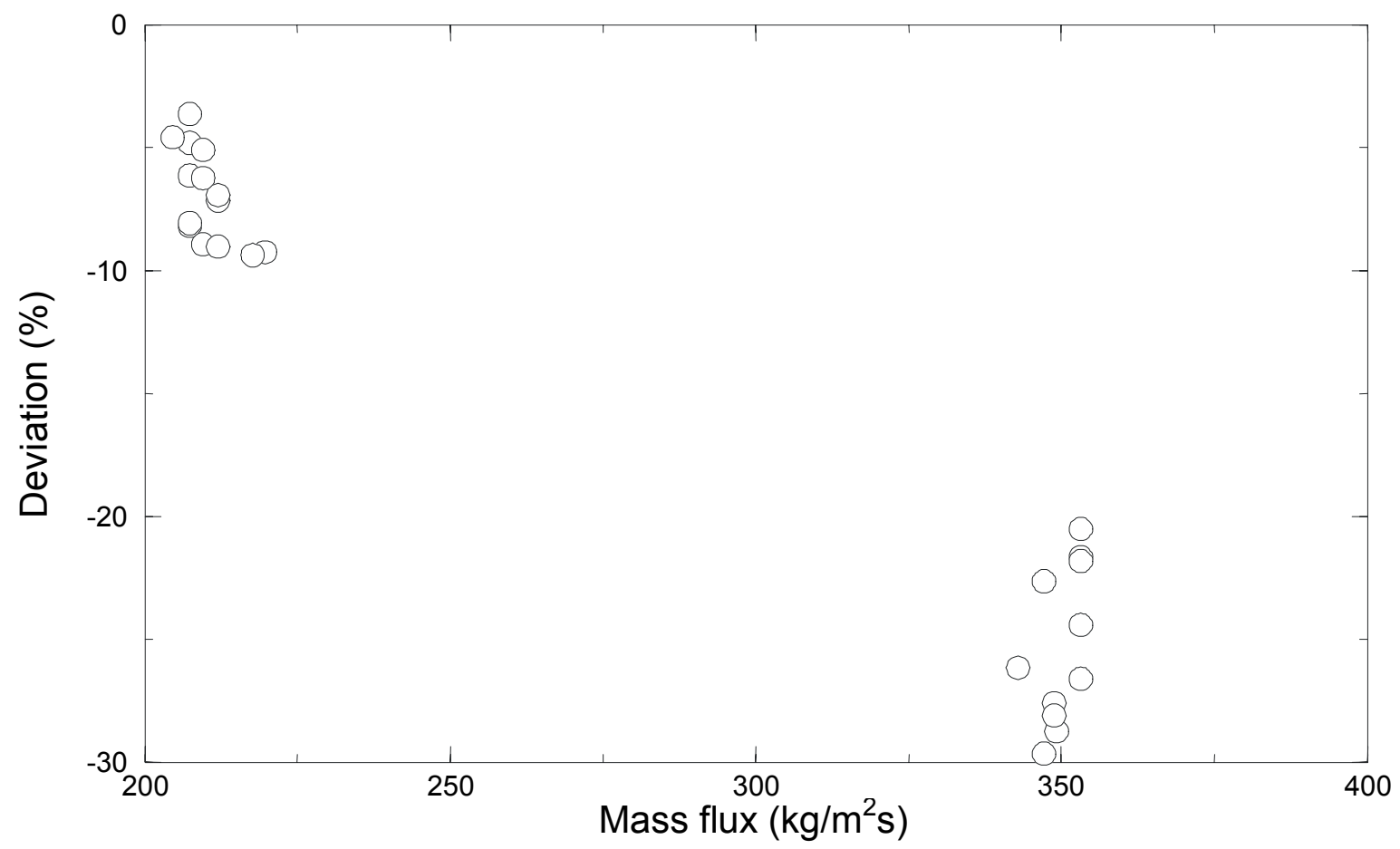

Figure 10. Calculated deviation from the measured CHF versus mass flux for the V-200 7-rod bundle.

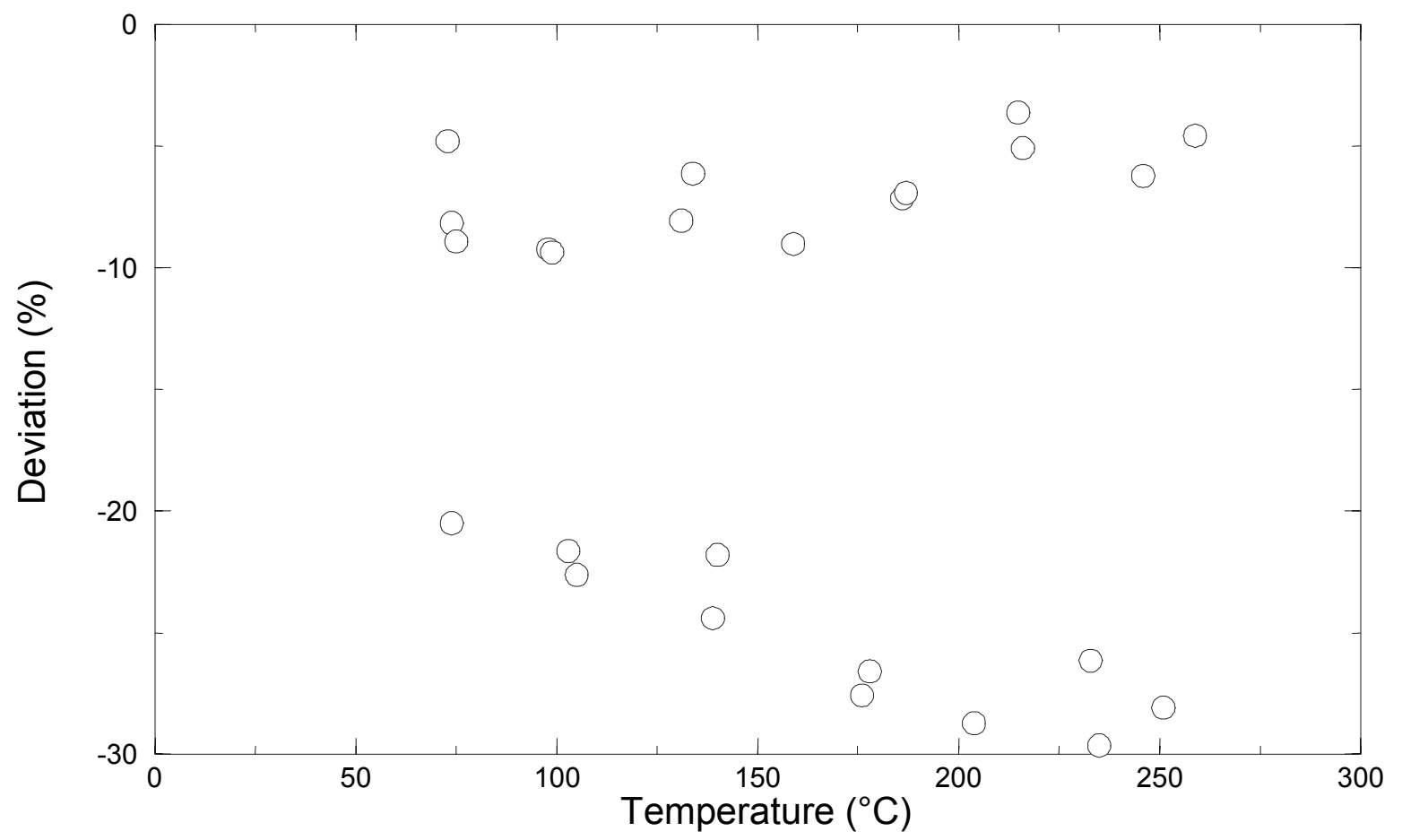

Figure 11. Calculated deviation from the measured CHF versus inlet temperature for the V-200 7-rod bundle. 
lower mass flux cases (smaller absolute deviations), the opposite trend is observed, with the deviation decreasing slightly as the temperature increased. With an estimated uncertainty of $10 \%$ in the measured CHF, the calculations are judged to be in excellent agreement with the lower mass flux test data but in minimal agreement with the higher mass flux data.

\subsubsection{Sensitivity Calculations}

Several sensitivity calculations were performed to investigate the impact of various parameters or code options on the CHF predictions. Five test points were used for each sensitivity study, with at least two lower mass flux points and two higher mass flux points.

There was essentially no difference from the base case for the sensitivity cases with increased or reduced heatup rates, increased axial nodalization (32 nodes over the heated length instead of 8 ), or an insulated outer wall modeled. Changes of less than $2 \%$ in the calculated CHF were obtained for sensitivity calculations in which the flow was reduced by its measurement uncertainty, or the pressure was increased or reduced by the measurement uncertainty.

In the final sensitivity calculations, all of the data points were recalculated using RELAP5/MOD3.2.1.2. This had a significant effect on the calculations, reducing each of the CHF values by $10-15 \%$, so that all of the lower mass flux CHF values were underpredicted and all of the higher mass flux CHF values were overpredicted. This resulted in a mean deviation of $-0.9 \%$ (the data slightly overpredicted), with a standard deviation of $9.8 \%$. The predictions of this version of the code are judged to be in excellent agreement with the data. 


\section{SUMMARY/CONCLUSIONS}

The RELAP5/MOD3.2 code has been assessed using CHF data from rod bundle tests in the KS-1 and V-200 experiment facilities. Three different sized rod bundles were used, with fluid conditions representative of those that might be encountered during a LOCA in a VVER plant after the initial blowdown.

The code overpredicted all of the CHF data, and the calculated values were generally outside the uncertainty band of the data. This leads to the conclusion that the code predictions are in minimal agreement with the measured data.

Figures 12 through 14 present the composite deviations for all three experiment facilities as functions of the pressure, mass flux, and measured CHF. The most noticeable trend is the increasing overprediction as the pressure decreases. The overprediction of the $\mathrm{CHF}$ also increased somewhat as the mass flux increased, although that trend appears to apply only below mass fluxes of about $1000 \mathrm{~kg} / \mathrm{m}^{2} \mathrm{~s}$. Aside from the grouping of low pressure values (deviations between $-75 \%$ and $-150 \%$ ), there was no apparent bias based on the measured CHF value. As was illustrated in Figures 7 and 11, there was also no apparent overall bias based on the inlet liquid temperature.

Several sensitivity calculations were performed for the KS-1 37-rod bundle and the V-200 7-rod bundle. None of these calculations, which addressed parameters such as loss coefficients, heatup rates, axial nodalization, and ambient heat loss, showed a significant improvement in the predicted CHF.

There is an error in the calculation of the equilibrium quality in the MOD3.2 version of the RELAP5 code, MOD3.2.1.2. The base case calculations for all three bundles were re-run with a newer version of the code, in which this error was corrected. The calculations for the KS-1 facility bundles showed little difference, but those for the V-200 7-rod bundle were reduced by $10-15 \%$, resulting in the data being well predicted by the code. It is not obvious why the code prediction changed significantly only for the smaller bundle. Those tests were run at only one pressure, and were for a much shorter bundle. It should also be noted that there were other differences in the two code versions besides the correction to the equilibrium quality, including a change in the interphase drag calculation as the flow transitions between the slug and annular flow regimes, which could affect the CHF calculation.

Based on the results of this assessment, it is recommended that a critical heat flux model that better simulates the behavior of VVER rod bundles be developed and incorporated into the RELAP5 code. 


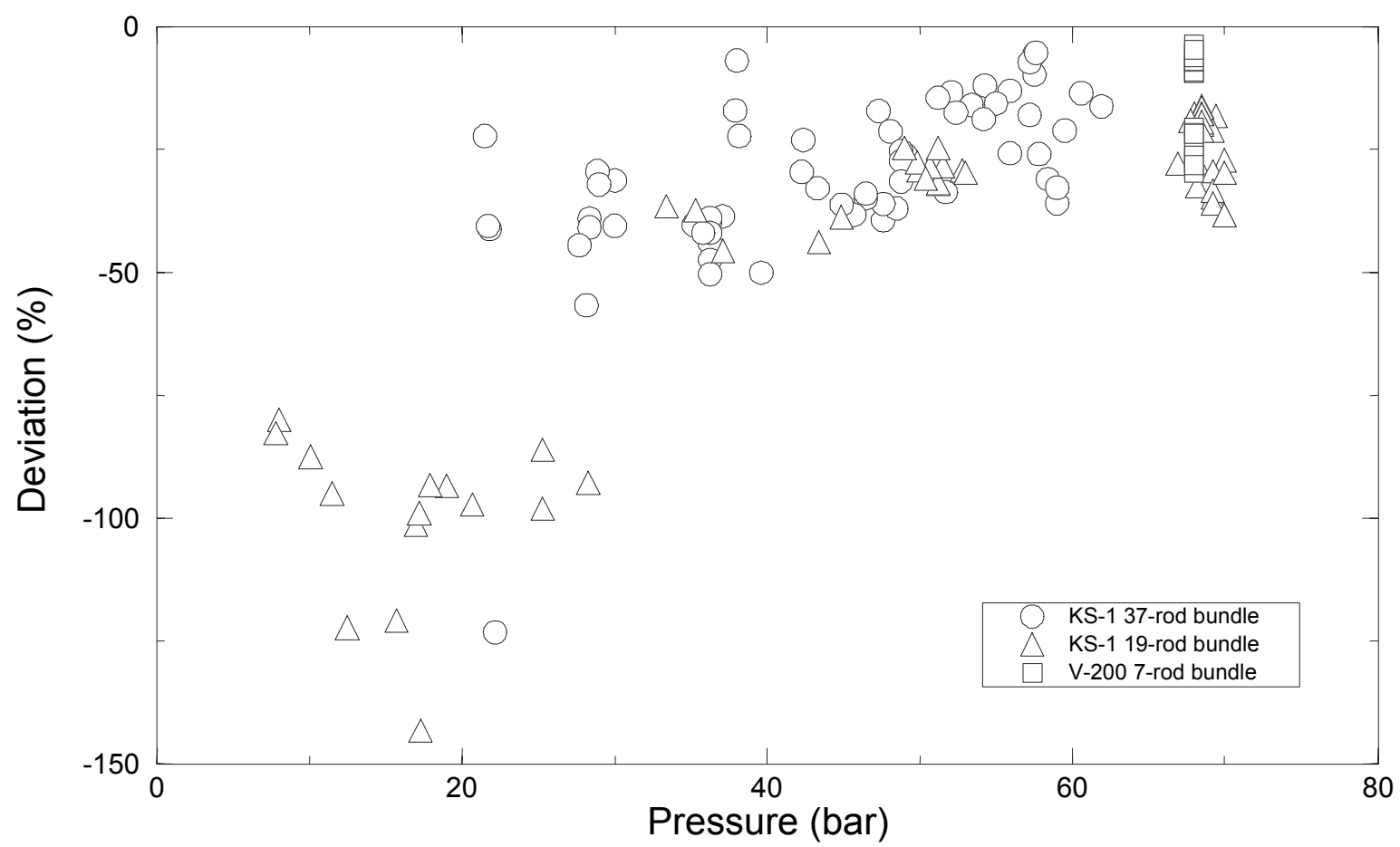

Figure 12. Calculated deviation from the measured CHF versus pressure for the three experiments.

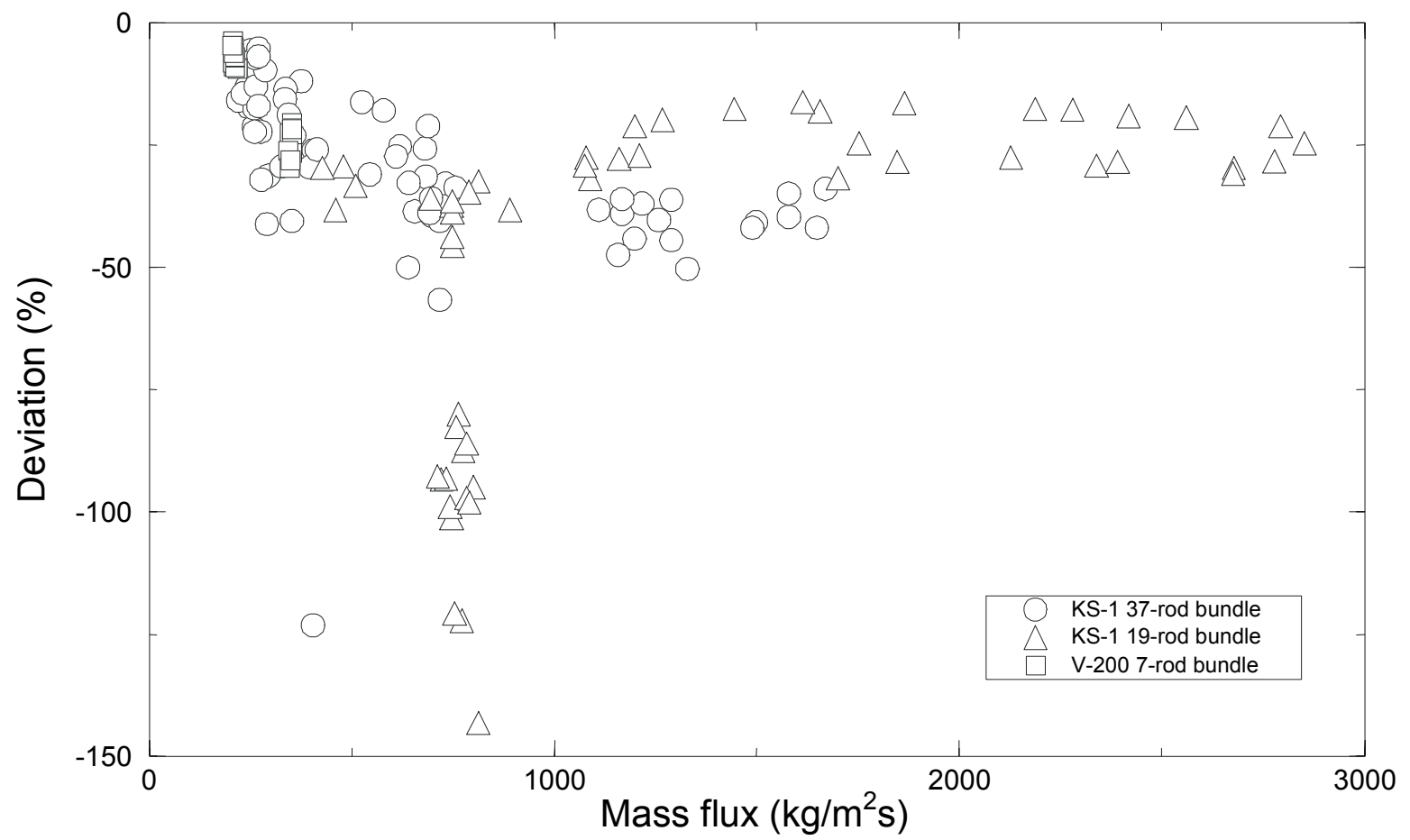

Figure 13. Calculated deviation from the measured CHF versus mass flux for the three experiments. 


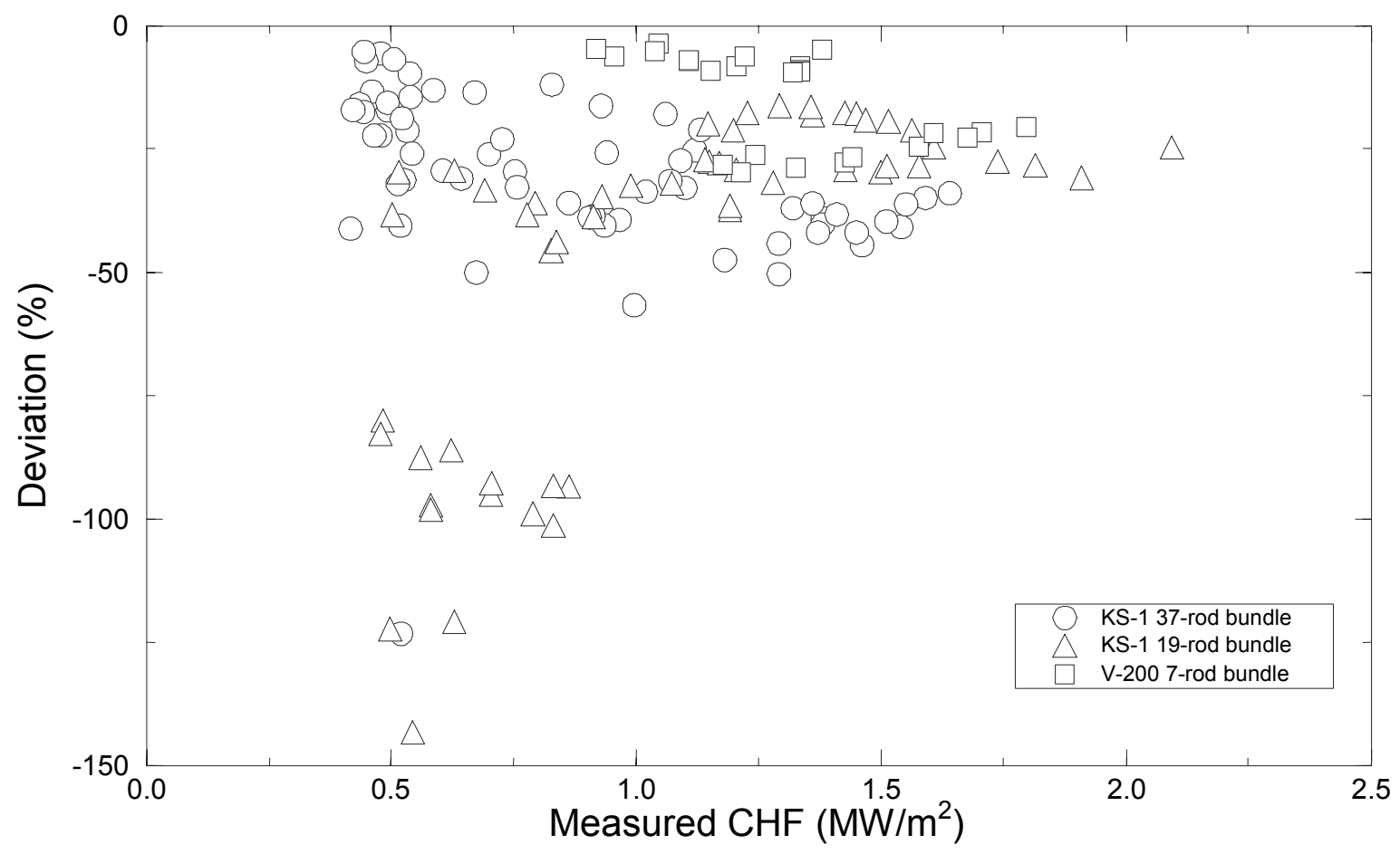

Figure 14. Calculated deviation from the measured CHF versus measured CHF for the three experiments. 


\section{REFERENCES}

1. V. N. Blinkov and A. G. Kraev, Computer Code Validation for Transient Analysis of VVER and RBMK Reactors, Phase 2, Final RELAP5 Validation Plan for Application to VVER, International Nuclear Safety Center, 1998.

2. V. N. Blinkov and A. G. Kraev, Computer Code Validation for Transient Analysis of VVER and RBMK Reactors, Phase 3, Standard Problem INSCSP-V7 Definition Report, VVER Core Heat Transfer, International Nuclear Safety Center, 2000.

3. Idaho National Engineering Laboratory, RELAP5/MOD3 Code Manual, NUREG/CR-5535, INEL-95/0174, August 1995.

4. P. A. Roth, Adequacy Evaluation of RELAP5/MOD3.2 for Simulating an ISB-VVER Standard Problem with a 2.4\% Coolant Leak, September 1998. 
Appendix A

Input Listing for KS-1 37-rod Bundle RELAP5 Model 


\section{Appendix A Input Listing for KS-1 37-rod Bundle RELAP5 Model}

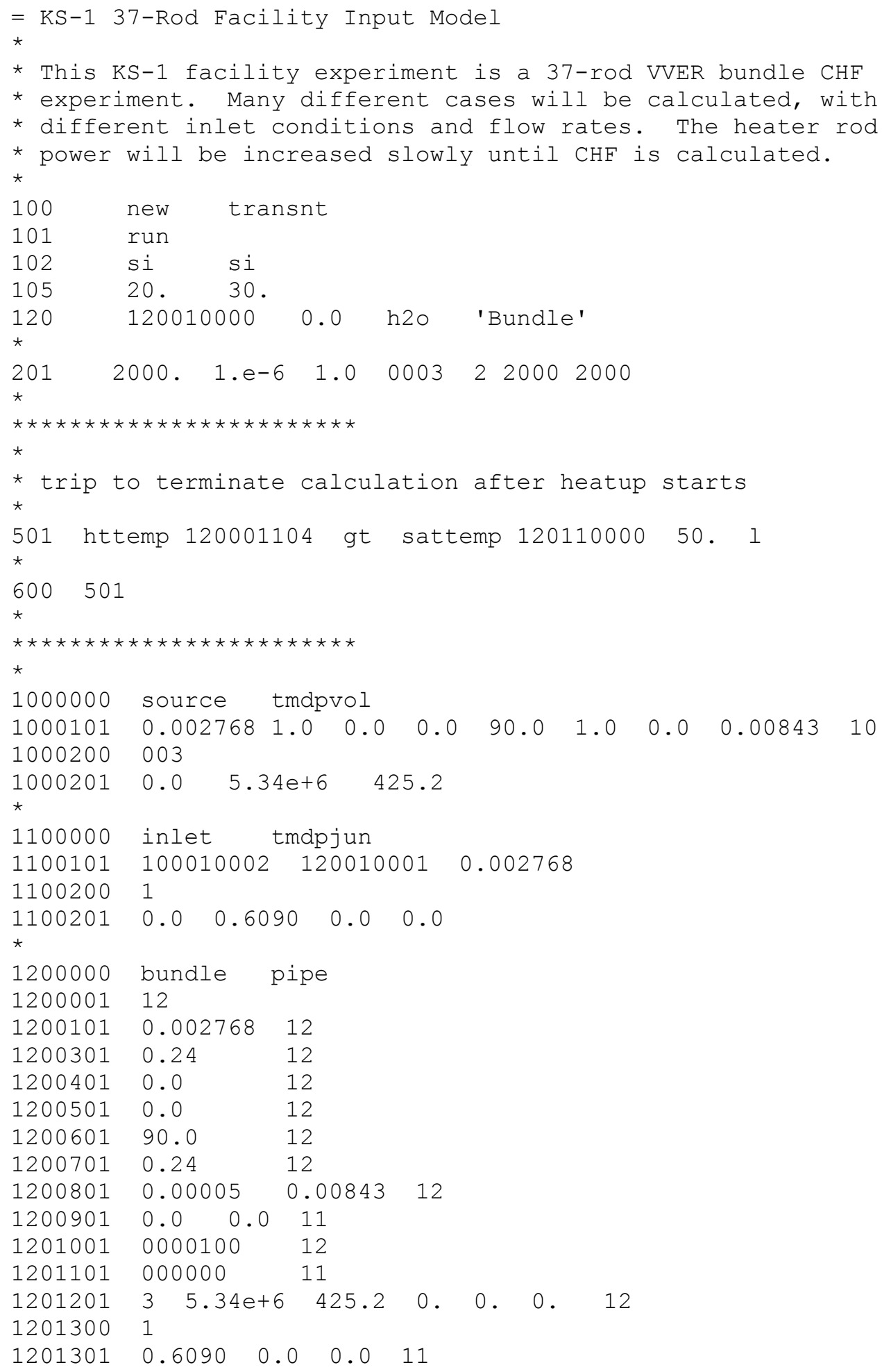




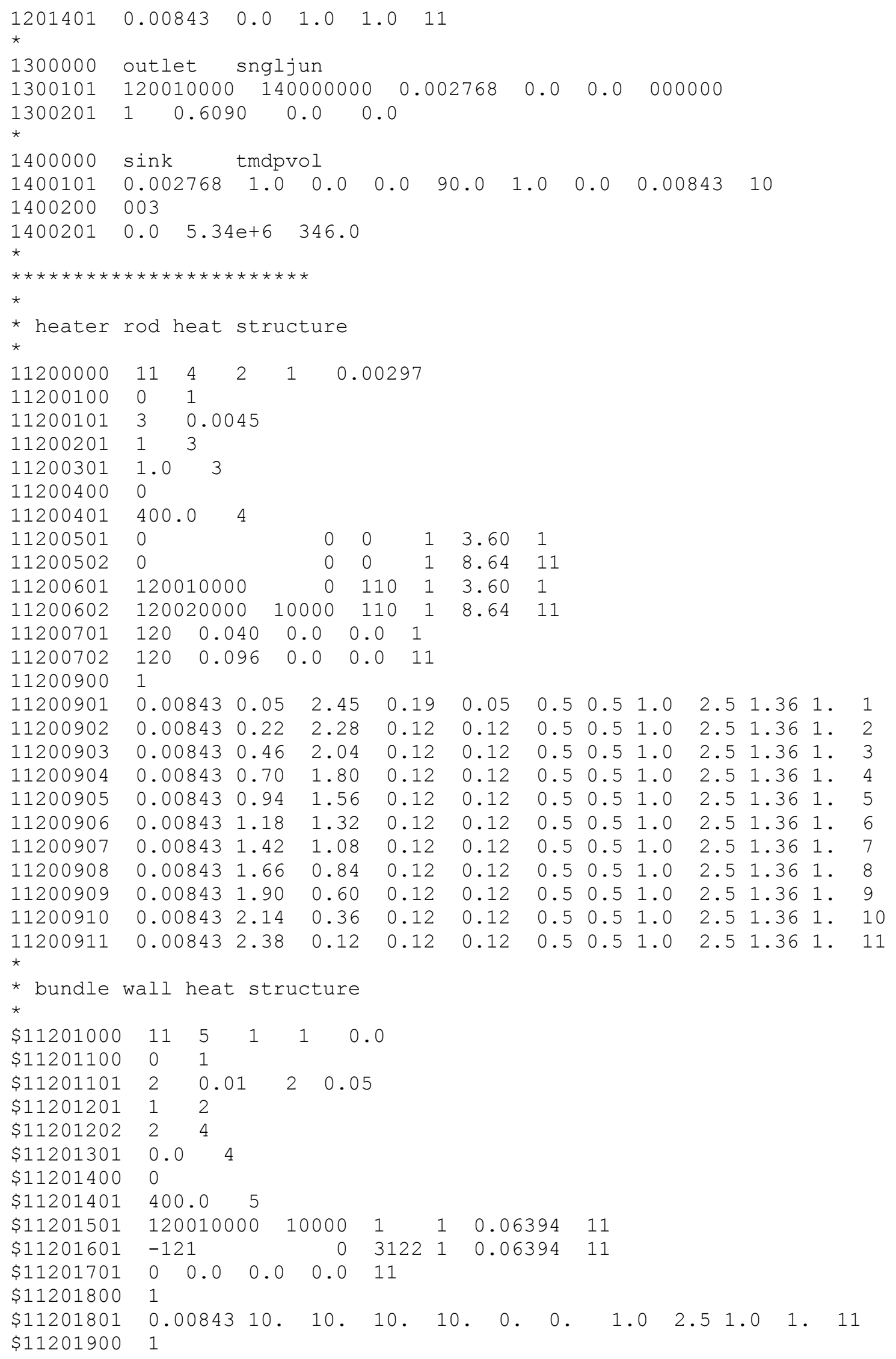




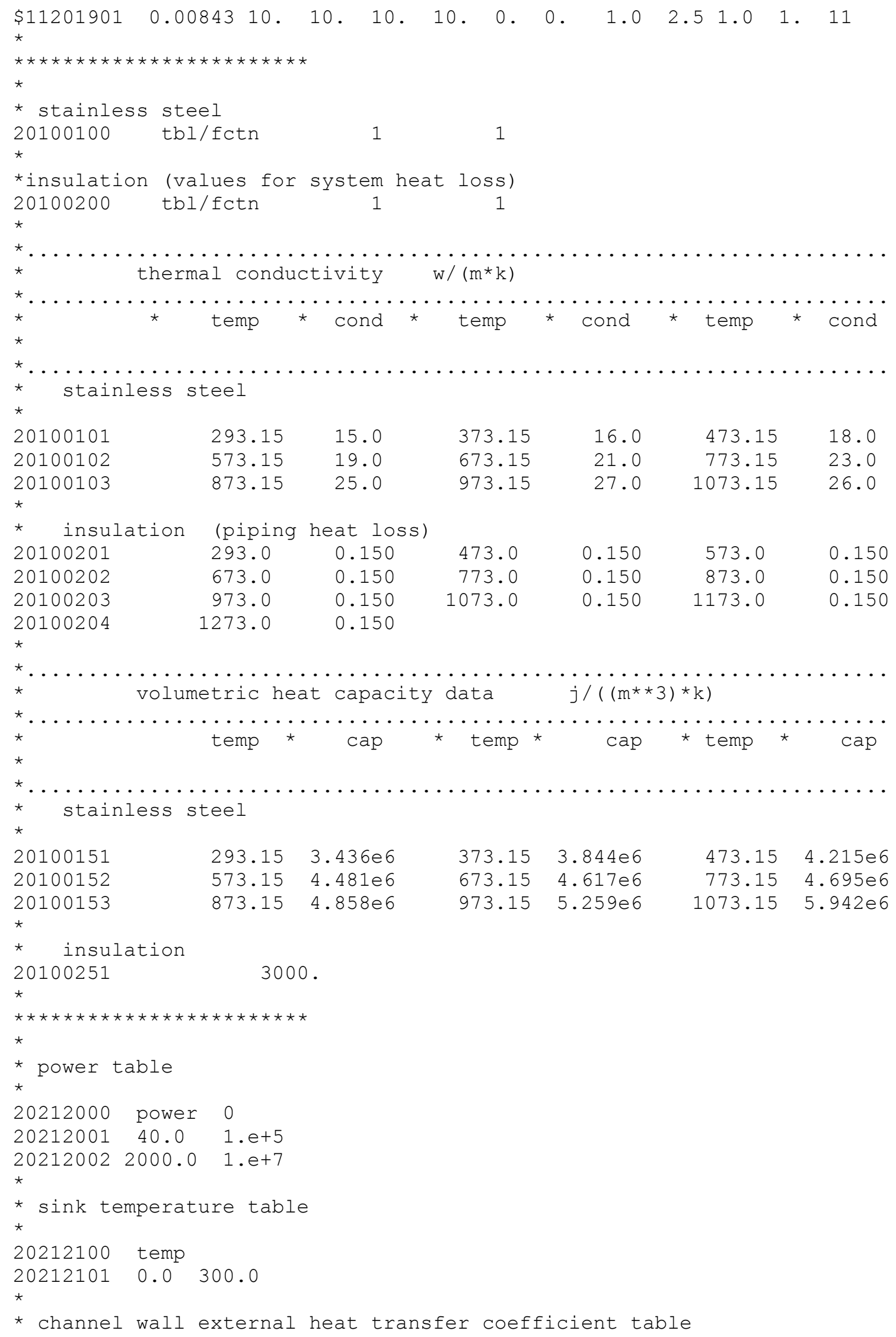




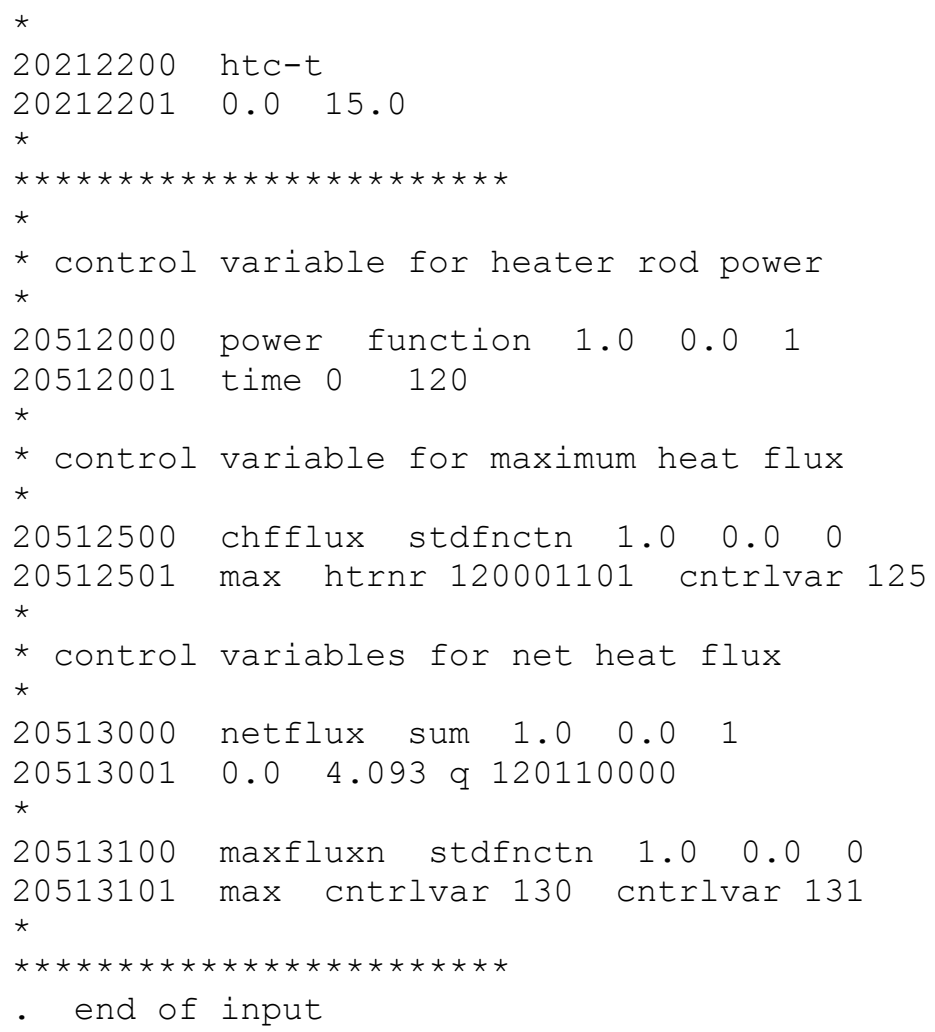




\section{Appendix B}

Input Listing for KS-1 19-rod Bundle RELAP5 Model 


\section{Appendix B Input Listing for KS-1 19-rod Bundle RELAP5 Model}

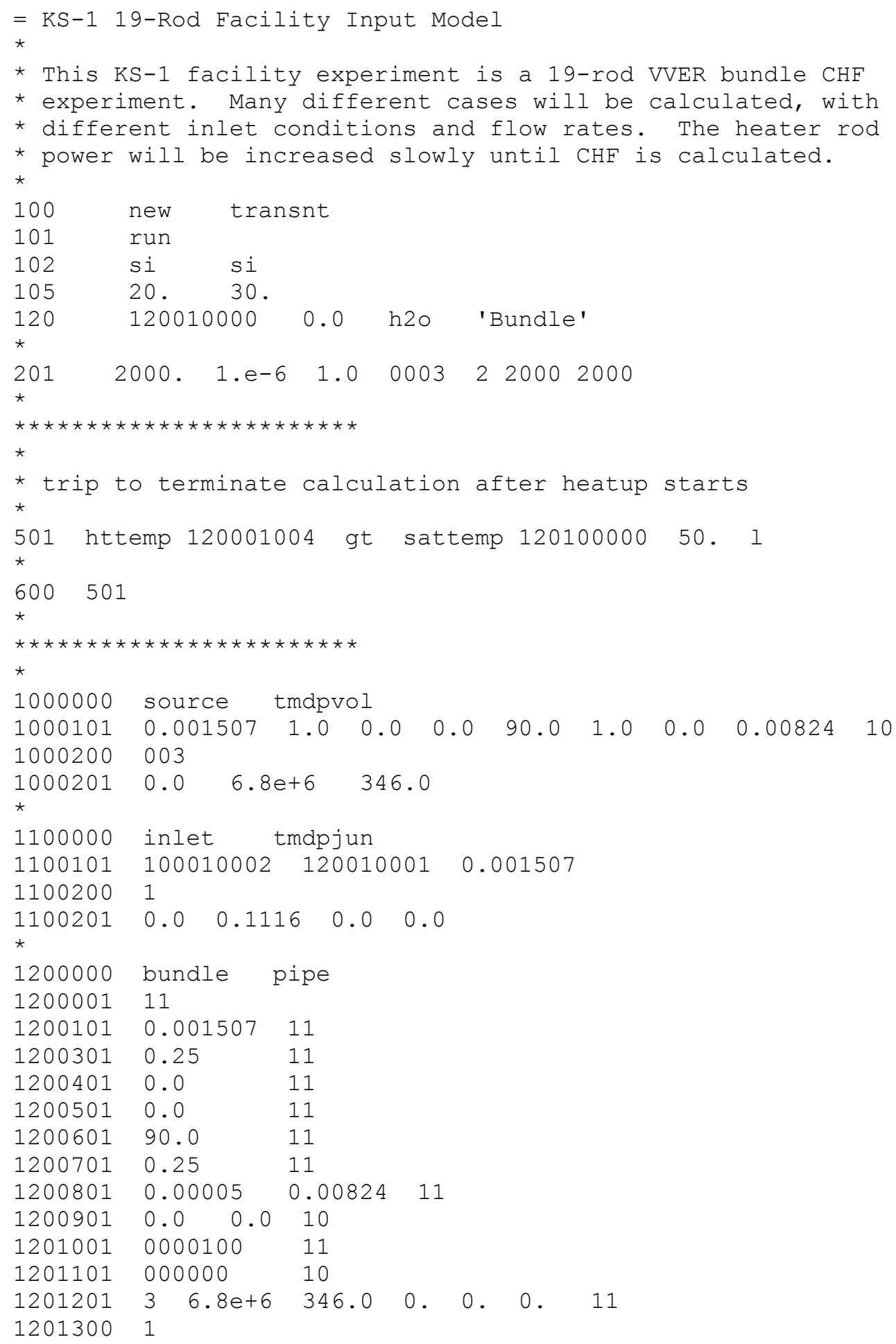




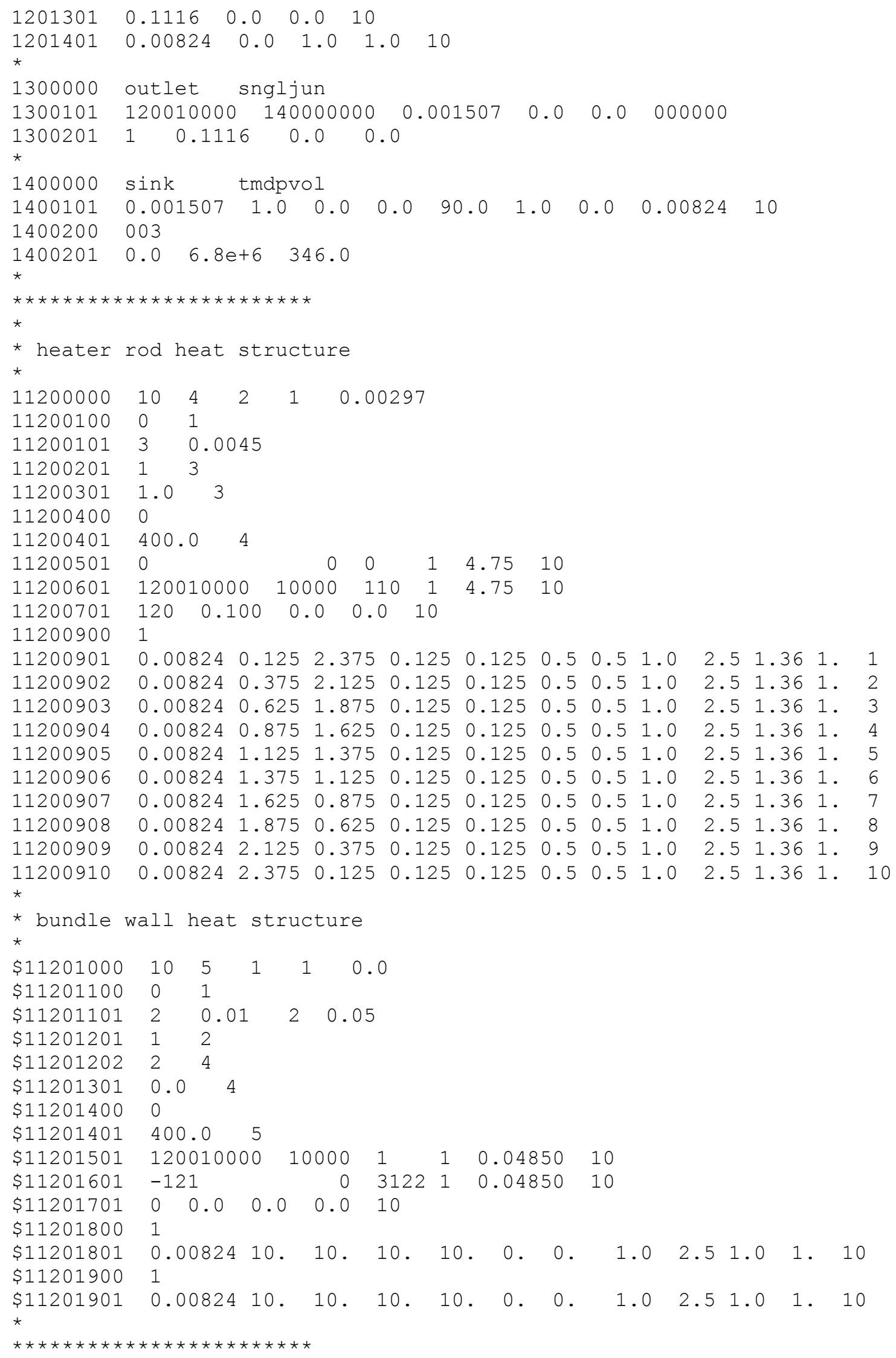




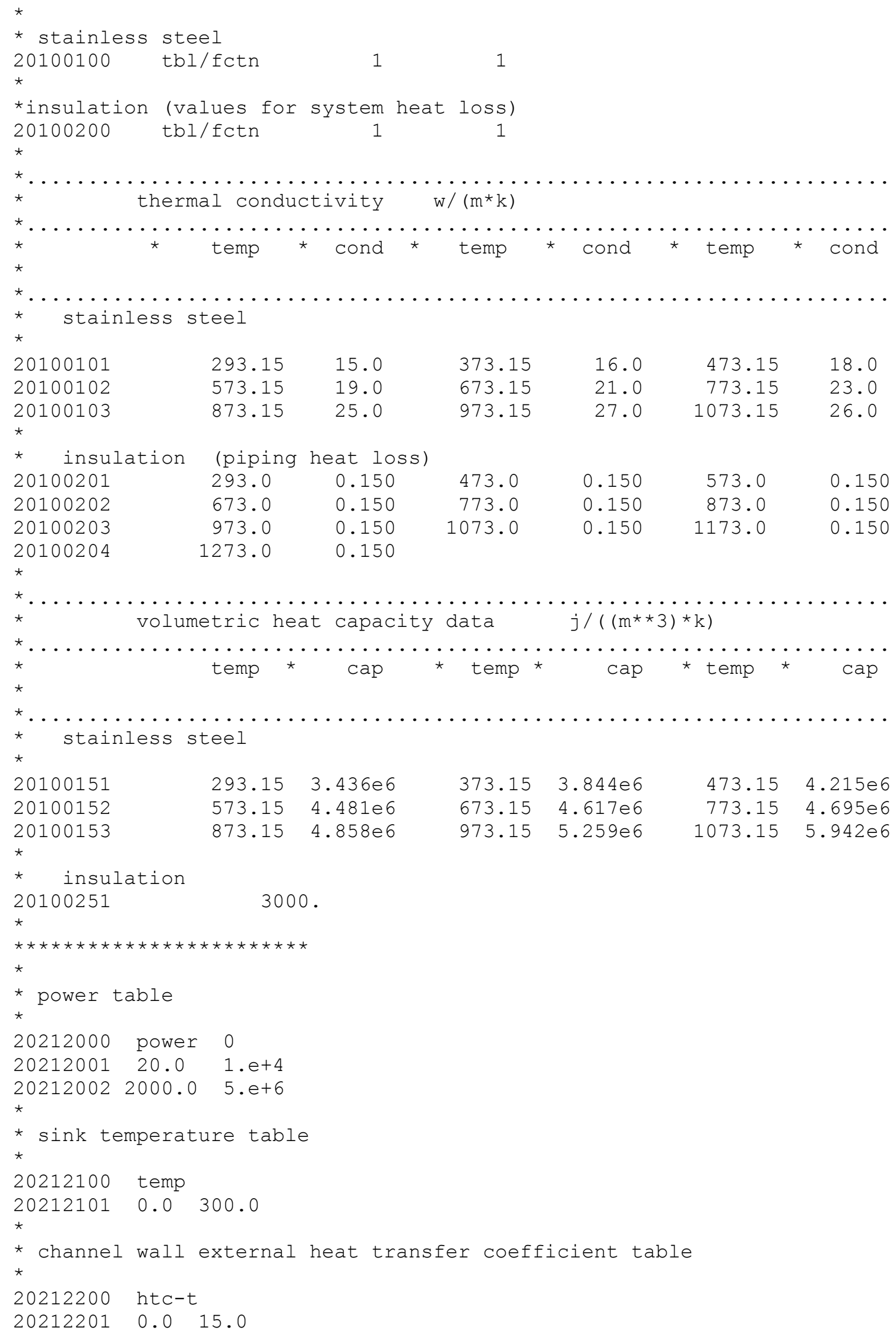




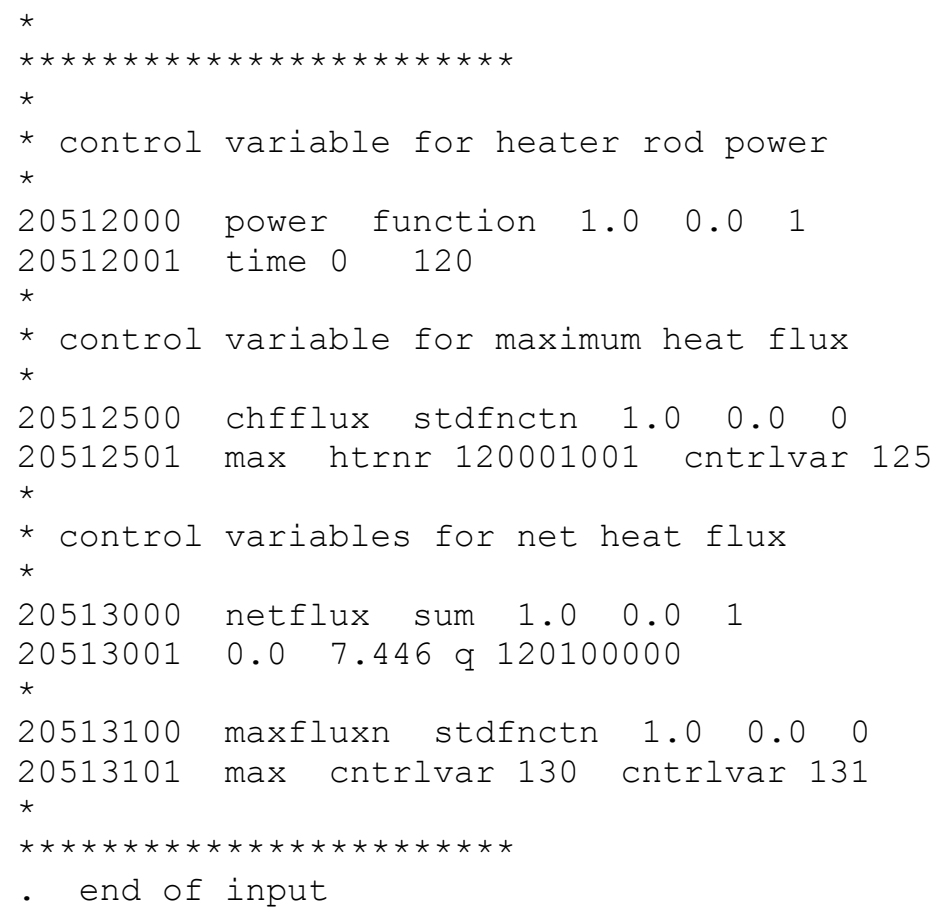

- end of input 
Appendix C

Input Listing for V-200 7-rod Bundle RELAP5 Model 


\section{Appendix C Input Listing for V-200 7-rod Bundle RELAP5 Model}

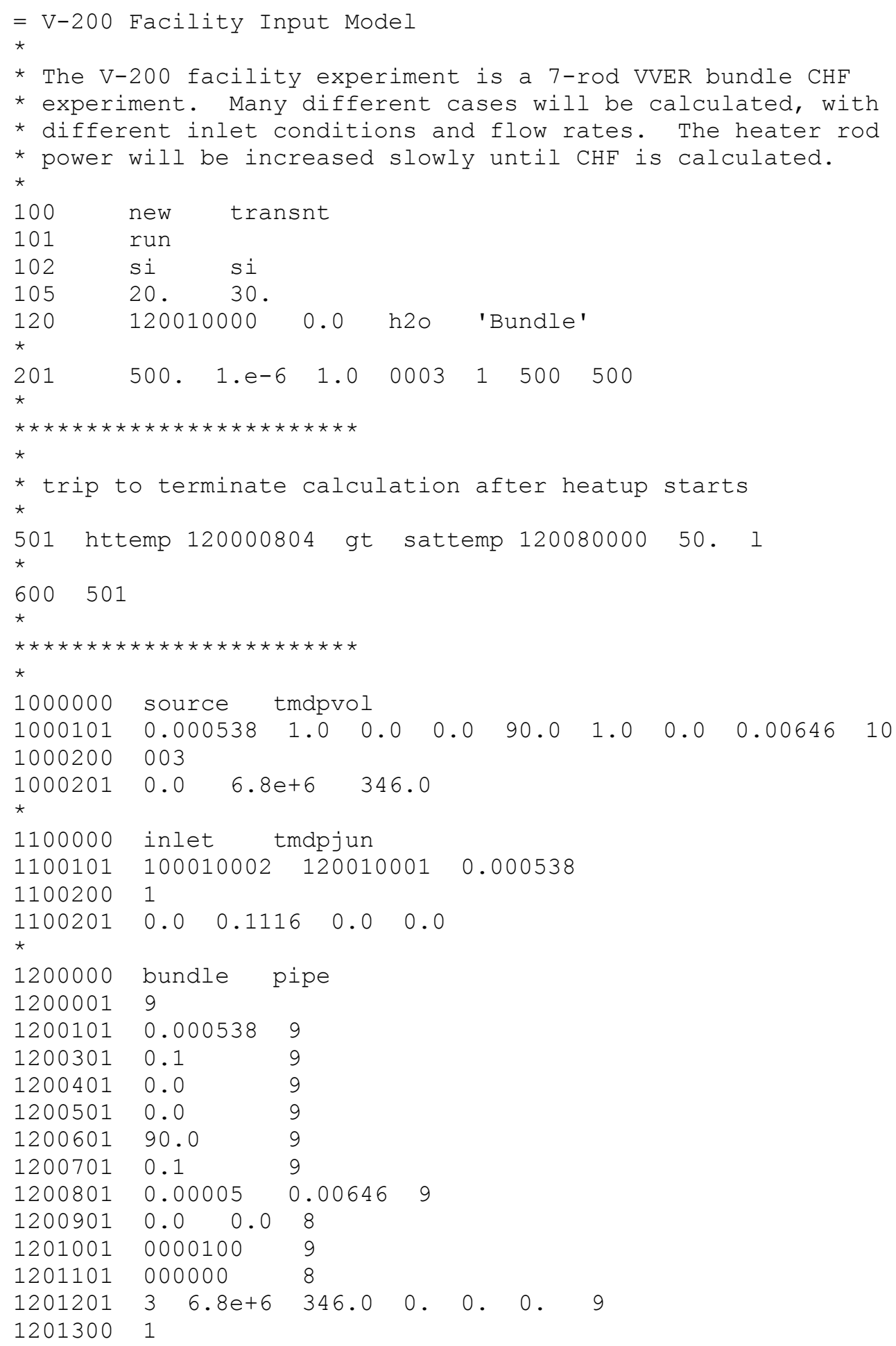




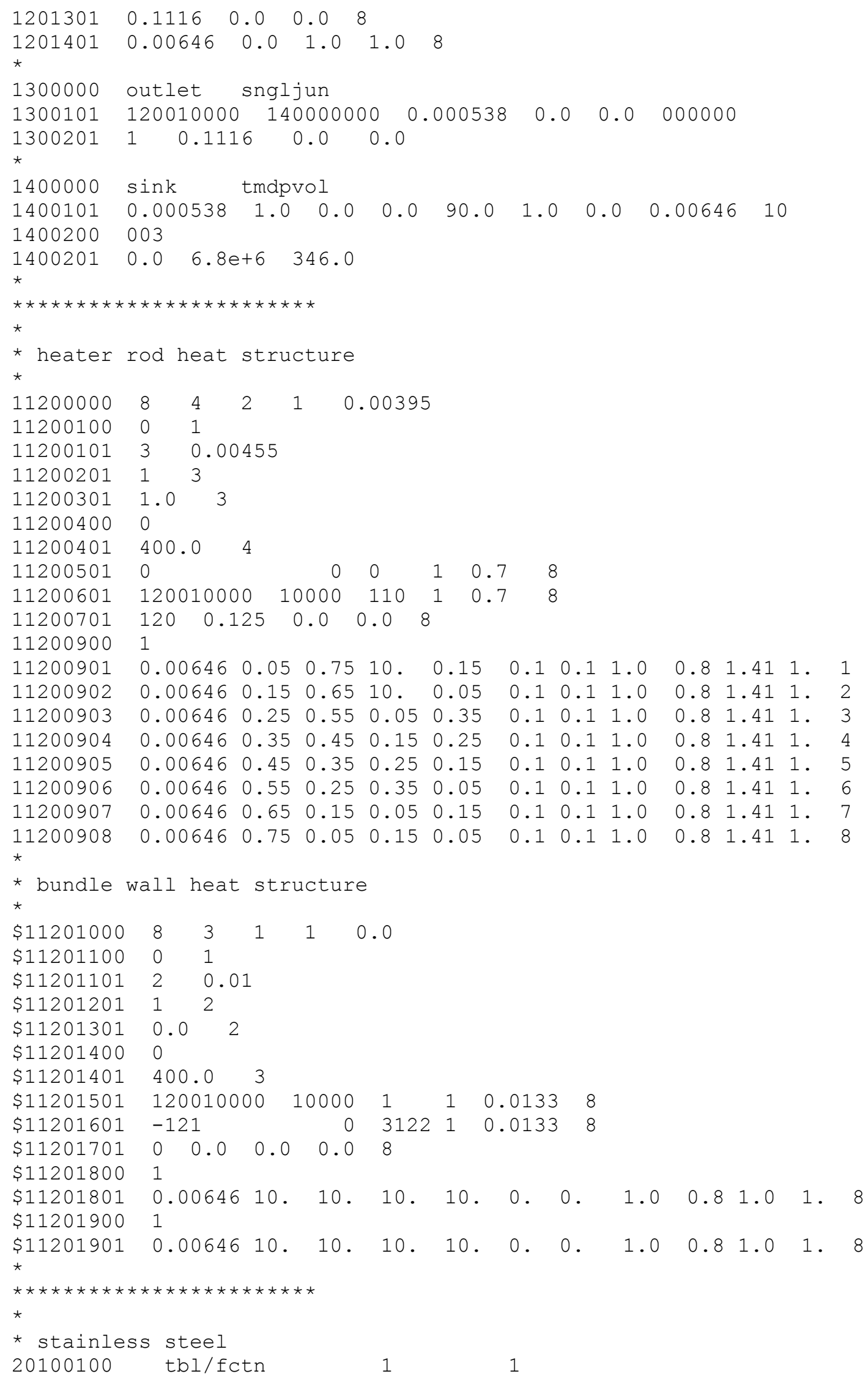




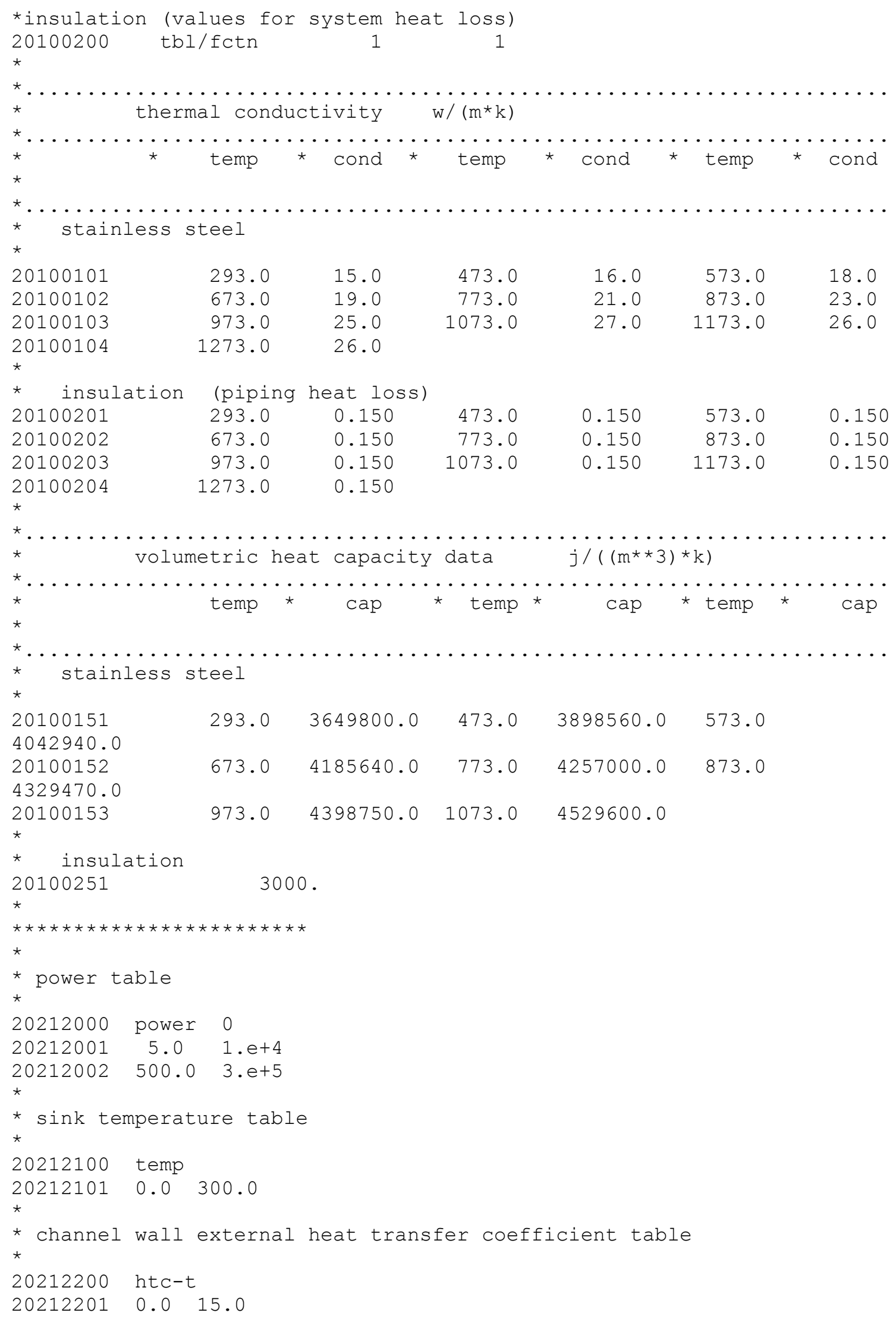




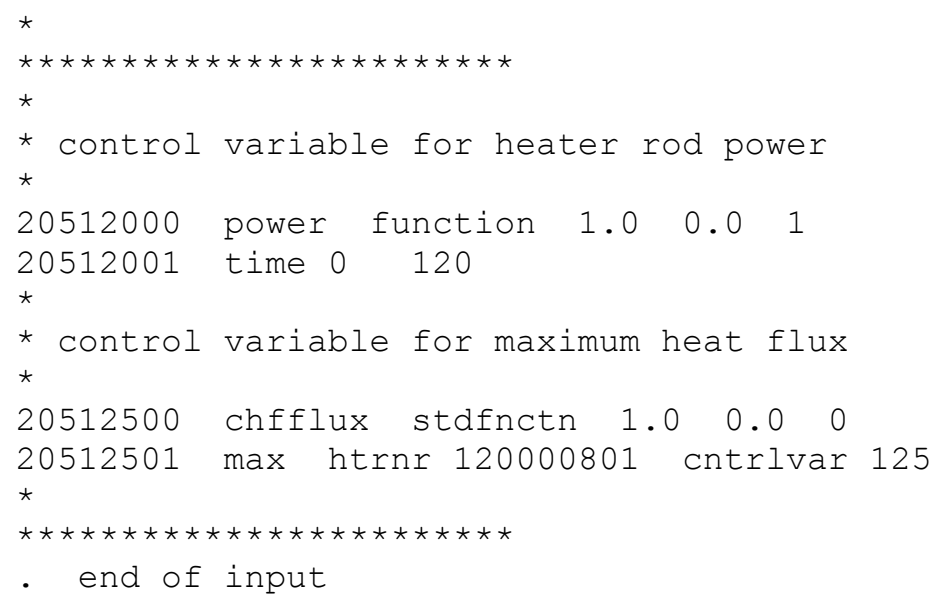

